NBER WORKING PAPER SERIES

THE POLITICAL ECONOMY OF TRANSPORTATION INVESTMENT

\author{
Edward L Glaeser \\ Giacomo A.M Ponzetto \\ Working Paper 23686 \\ http://www.nber.org/papers/w23686 \\ NATIONAL BUREAU OF ECONOMIC RESEARCH \\ 1050 Massachusetts Avenue \\ Cambridge, MA 02138 \\ August 2017
}

We thank Kevin Chen for excellent research assistance, and Stephen Coate, Gilles Duranton and seminar participants at the NBER Summer Institute for helpful comments. We acknowledge financial support from the Taubman Center for State and Local Government, the European Research Council under the European Union's Horizon 2020 research and innovation program (grant agreement n. 714905), the Spanish Ministry of Economy and Competitiveness (grants RYC-2013-13838 and SEV-2015-0563), and the Government of Catalonia (CERCA program and grant 2014 SGR 830). The views expressed herein are those of the authors and do not necessarily reflect the views of the National Bureau of Economic Research.

At least one co-author has disclosed a financial relationship of potential relevance for this research. Further information is available online at http://www.nber.org/papers/w23686.ack

NBER working papers are circulated for discussion and comment purposes. They have not been peer-reviewed or been subject to the review by the NBER Board of Directors that accompanies official NBER publications.

(C) 2017 by Edward L Glaeser and Giacomo A.M Ponzetto. All rights reserved. Short sections of text, not to exceed two paragraphs, may be quoted without explicit permission provided that full credit, including $\odot$ notice, is given to the source. 
The Political Economy of Transportation Investment

Edward L Glaeser and Giacomo A.M Ponzetto

NBER Working Paper No. 23686

August 2017

JEL No. D72,D82,H54,H76,R42,R53

\begin{abstract}
$\underline{\text { ABSTRACT }}$
Will politics lead to over-building or under-building of transportation projects? In this paper, we develop a model of infrastructure policy in which politicians overdo things that have hidden costs and underperform tasks whose costs voters readily perceive. Consequently, national funding of transportation leads to overspending, since voters more readily perceive the upside of new projects than the future taxes that will be paid for distant highways. Yet when local voters are well-informed, the highly salient nuisances of local construction, including land taking and noise, lead to under-building. This framework explains the decline of urban mega-projects in the US (Altshuler and Luberoff 2003) as the result of increasingly educated and organized urban voters. Our framework also predicts more per capita transportation spending in low-density and less educated areas, which seems to be empirically correct.
\end{abstract}

\author{
Edward L Glaeser \\ Department of Economics \\ 315A Littauer Center \\ Harvard University \\ Cambridge, MA 02138 \\ and NBER \\ eglaeser@harvard.edu \\ Giacomo A.M Ponzetto \\ CREI, Universitat Pompeu Fabra, and Barcelona GSE \\ C/ Ramon Trias Fargas, 25-27 \\ 08005 Barcelona \\ Spain \\ gponzetto@crei.cat
}




\title{
The Political Economy of Transportation Investment*
}

\author{
Edward L. Glaeser \\ Harvard University \\ Giacomo A. M. Ponzetto \\ CREI, Universitat Pompeu Fabra, IPEG and Barcelona GSE
}

August 2017

\begin{abstract}
Will politics lead to over-building or under-building of transportation projects? In this paper, we develop a model of infrastructure policy in which politicians overdo things that have hidden costs and underperform tasks whose costs voters readily perceive. Consequently, national funding of transportation leads to overspending, since voters more readily perceive the upside of new projects than the future taxes that will be paid for distant highways. Yet when local voters are well-informed, the highly salient nuisances of local construction, including land taking and noise, lead to under-building. This framework explains the decline of urban mega-projects in the US (Altshuler and Luberoff 2003) as the result of increasingly educated and organized urban voters. Our framework also predicts more per capita transportation spending in low-density and less educated areas, which seems to be empirically correct.
\end{abstract}

Keywords: Infrastructure, Political economy, Transportation investment, Nuisance mitigation, Elections, Imperfect information

JEL codes: D72, D82, H54, H76, R42, R53

\section{Introduction}

Should we expect democratic governments to provide the socially optimal level of transportation infrastructure, or will the democratic process lead to either over- or underinvestment? Like all public actions, transportation decisions will be shaped not only by voter preferences

\footnotetext{
*E-mail: eglaeser@harvard.edu, gponzetto@crei.cat. We thank Kevin Chen for excellent research assistance, and Stephen Coate, Gilles Duranton and seminar participants at the NBER Summer Institute for helpful comments. We acknowledge financial support from the Taubman Center for State and Local Government, the European Research Council under the European Union's Horizon 2020 research and innovation program (grant agreement n. 714905), the Spanish Ministry of Economy and Competitiveness (grants RYC2013-13838 and SEV-2015-0563), and the Government of Catalonia (CERCA program and grant 2014 SGR $830)$.
} 
but also by voter attention. Costs that are obvious, like the inconvenience of a freeway to neighbors, will carry more weight than costs that are hidden, like the budgetary costs of federal transfers for future generations. Groups that are better informed and more politically active will receive more benefits than the ill informed and the inactive.

The power of attention can explain why parties don't converge on the preferred policies of the median voter. If different parties communicate disproportionately with different groups, such as labor unions and churches, then they will skew their policies to please the voters who are listening more to their messages (Glaeser, Ponzetto and Shapiro 2005). If the workers in protected industries pay more attention to tariff policy than consumers, then protectionism will become attractive politics (Ponzetto 2011). If the value of future pension and health care benefits are more salient to municipal workers than their costs are to voters, then public workers will be paid disproportionately in such shrouded forms of compensation (Glaeser and Ponzetto 2014).

In this paper, we apply the logic of political attention to transportation investment. In Section II, we begin by discussing the arc of investment described Altshuler and Luberoff (2003). Their definitive study of post-war American mega-projects describes three periods. Initially, US cities, supported with federal subsidies, build mega-projects and largely ignore the downsides of this building to local residents. In the second period, local opposition, such as the Freeway Revolts, blocks many of these projects. In the third period, mega-projects reappear, but they are even more expensive because builders take great care to avoid harming local residents.

While this arc is overly simplistic, it suggests that America may have gone from a period of overbuilding to a period of underbuilding and perhaps over-abatement of the downsides of construction. Our model is meant to explain this transition and yield other testable implications about infrastructure investment. We highlight two ways in which voter attention skews transportation spending: spending elsewhere is not salient while local nuisances are extremely salient.

The first distortion assumes that while voters can easily see the benefits of a new highway, they don't pay much attention to the marginal dollar added to the federal budget. Consequently, when the federal government starts funding infrastructure, the incentive to spend becomes stronger even when spending decisions are made at the national level. Our attention model yields a microfounded version of Weingast's (1979) "Law of 1/N" in which spending proceeds as if benefits are weighed only against each jurisdiction's share of total costs. This force will lead to too much spending, and may perhaps explain why America experienced so much investment during the early postwar period.

The second distortion is that the physical downsides of construction are even more salient to the neighbors of new infrastructure than the benefits of that infrastructure are to its users. Those physical downsides include noise, pollution and the use of eminent domain to acquire land. The salience of these costs is well illustrated by the popular fury that erupted in the Freeway Revolts and by the ardent opposition to private and public construction that exists in many parts of the US today.

This second force can lead to underprovision of transportation infrastructure and explain why the era of big building yielded to an era of infrastructure caution. As urban residents became better educated and better organized, the salience of these local costs became more important to electoral politics. The salience of these costs to educated voters is one expla- 
nation of the rise of "Not in My Back Yard"-ism or NIMBYism. The model also predicts that once the harmed are sufficiently well informed, infrastructure investment will decline with their income levels.

Our model shows that a perfectly calibrated federal funding strategy can exactly offset the salience of local costs and yield the socially optimal level of transportation investment. The ideal share of federal spending rises with the knowledge mismatch between the local winners and losers from transportation investment. The optimal federal subsidy also rises with the nuisance costs of construction and the benefits of transportation to users, assuming that the urbanites who suffer the costs are better informed.

Yet we suspect that this optimistic scenario is unlikely to reflect reality, especially because a national funding policy cannot be well tailored to local conditions. A funding strategy that yields optimal infrastructure in dense and well-educated San Francisco is likely to be far too generous to yield optimal infrastructure investment in less dense and more poorly educated parts of America. Our model predicts that holding the federal spending share constant, we should see more per capita investment in low density areas and less investment in higher density areas.

We then include abatement investment to capture Altshuler and Luberoff's (2003) third era of mega-projects. Abatement investments reduce the costs of infrastructure to local residents, and one example might be routing the infrastructure so that it avoids any dense neighborhoods and any use of eminent domain. Once we allow abatement investment, then a single federal funding share cannot yield an efficient level of abatement and an efficient level of investment. If knowledge is particularly high among those harmed by infrastructure, then this will require a generous federal funding share, but that will also produce an excess of abatement investment. This logic suggests that third era projects, like Boston's Big Dig, may have spent too much on abating local nuisances.

We focus on spending decisions that are determined at the national level, but we also consider the impact of local control over spending. Typically, local control and financing will lead to underinvestment, because local voters don't consider the benefits to outsiders. When localities receive a federal subsidy share of costs, then the optimal subsidy can be either smaller or larger than with national decision-making, because while local voters don't consider the tax implications to outsiders, they also don't consider the infrastructure benefits to outsiders.

User fee financing will also impact investment because of its salience. When user fees are more salient than taxes, then user fee financing will tend to reduce investment. When federal funding cannot achieve the first best on its own, then user fees can be used to fine tune the investment.

In Section VIII, we briefly discuss added implications of our model. We predict that there will be more spending in low-density areas than in high-density areas, because salient nuisances from construction are more common in density areas. Recent within-state spending patterns strongly support this implication.

We also predict that highways will be sited in less education areas, since less educated people are typically less politically aware and less politically active (Galston 2001). A robust literature shows that less educated people are more likely to live near highways. Yet that pattern also reflects post-construction geographic mobility. Brinkman and Lin (2016) is the one paper we know that seems to show that highways are built in less successful neighborhoods. 
Our model also predicts that spending on abatement will be more common in more educated areas. We lack direct data on abatement spending. However, there is a strong pattern that better educated states have larger highway disbursements per mile. One interpretation of this fact is that these states are spending more to reduce the downsides of highways, but that is more of a hypothesis than a fact.

Finally our model predicts that national control will lead to more spending in places that receive more outside visitors. A comparison of the US and the UK appears to support this fact, since US transportation spending skews towards lower density states, while UK spending skews towards London, which receives millions of visitors from elsewhere in the UK. We hope that future work will provide more serious tests of our model.

This paper highlights two offsetting ways in which politics distorts transportation spending. The national funding of local projects ensures too little attention to the financial costs of those projects. The highly salient nature of local nuisances ensures that too much weight will be given to those nuisances. In an ideal world, these two political failures balance each other out, but we doubt that they do in reality.

Our paper follows a growing theoretical literature on the connection between voter knowledge and political outcomes. Coate and Morris (1995) pioneered this literature, showing that politicians will transfer in opaque and inefficient ways to reduce punishment by voters. Gavazza and Lizzeri (2009) show that limited transparency can shape the flow of transfers and increase debt levels. Glaeser and Ponzetto (2014) similarly show how limited observability leads to excessive use of shrouded forms of compensation for government employees, such as pensions and health care. Boffa, Piolatto and Ponzetto (2016) explore how voter information shapes the optimal federal structure of government, which relates to our investigation of the impact of federal funding on transportation projects.

Our paper also follows a small but distinguished literature on the political economy of transportation. Knight (2005) shows that constituencies whose US representatives belong to the House Committee on Transportation and Infrastructure receive more infrastructure spending. Brueckner and Selod (2006) show that heterogeneity within a city can lead to underinvestment in transportation. De Borger and Proost (2016a) examine the federal role in transportation spending, and find that in the absence of institutional constraints, local decision-making outperforms national decision-making when the majority of voters use the infrastructure. De Borger and Proost (2016b) find that the presence of institutional constraints, such as uniform road pricing, may lead federal decision-making to outperform local decision making.

\section{The Rise and Decline of Megaprojects}

Between 1926 and 1939, America built six suspension bridges with central spans that exceeded 500 meters, and four of these were, at the time, the longest in the world. Since 1964, we have built only two such bridges. While the earlier bridges were often in the heart of great metropolitan areas, the two more recent bridges were in far less dense settings. American construction of long tunnels and urban highway miles has also slowed dramatically relative to the post-war heyday of construction.

Altshuler and Luberoff's (2003) Mega-Projects provides the definitive history of America's 
twentieth-century urban infrastructure building. They describe three distinct phases. In the first phase, which largely ran until the early 1960s, building proceeded with federal support and little concern over local opposition. During that period, massive projects, including New York's Lincoln Center, Chicago's Dan Ryan Expressway, and San Francisco's Golden Gate Bridge, were constructed in the heart of metropolitan areas.

During the second phase, community opposition coalesced, with early leaders such as Shirley Hayes and Jane Jacobs. These groups borrowed techniques from the civil rights movement, and convinced urban leaders, such as Carmine DeSapio, that pushing controversial projects was not in their political self-interest. The third phase saw mega-projects commence again, but with far more attention to community concerns. Boston's Big Dig is their poster child for this third phase, in which builders, like Fred Salvucci, were willing to spend billions to avoid disturbing neighbors.

A slight variation on their view is that community strength has grown more or less continually since the mid-1950s. Activists have made it more and more difficult to build projects, unless these projects are, like the Big Dig, wrapped up in extremely expensive protections against community harm and accompanied with other benefits for local residents. This view emphasizes that the current environment is just far more restrictive than the earlier era.

Three forces generated the spurt in infrastructure construction prior to 1964. First, America's cities grew massively in the decades before 1930. New York's population doubled from 3.4 million to almost seven million between 1900 and 1930; Chicago's population increased from 1.7 million to 3.38 million over the same three decades. The vast increase in population increased the potential benefits from better transportation connections, especially since, after 1898, New York City sprawled over five boroughs, not just the island of Manhattan.

Second, a new transportation technology - the automobile - had emerged in the last years of the nineteenth century. America's older cities were built around very different transportation technologies, and drivers could benefit enormously from limited-access highways, bridges and tunnels. Master builder Robert Moses began his infrastructure career building parkways in Long Island during the 1920s. Well-educated and wealthy suburbanites were one natural constituency for these projects. Many of the large mid-century infrastructure projects, and the later Big Dig, can be seen as attempts to retrofit the city for the car.

Third, the Great Depression saw an unprecedented increase in federal funding for local infrastructure projects. The federal government had supported transportation linkages, including canals and the intercontinental railroad, since the nineteenth century. The economic downturn, however, turned infrastructure into a counter-recessionary tool, and federal infrastructure money flowed to local leaders, like New York's Fiorello La Guardia. Eisenhower maintained the national interest in funding infrastructure through his support of the highway system.

Rising urban populations, the car and Federal funding produced the first era of expansive infrastructure, epitomized perhaps by Robert Moses, who built highways, bridges, pools and parks throughout the greater New York area. During the 1950s, Moses first started experiencing pushback against his proposals. The organized opposition emerged first among better-educated pockets of the population.

Robert Caro's (1974) biography of Moses highlights two early defeats for the builder: his 
proposal to run Fifth Avenue through Washington Square Park in 1952, and an expanded parking lot for Tavern on the Green in 1956. In both cases, Moses was trying to make New York City more car friendly. In both cases, well-heeled New Yorkers opposed Moses by organizing letter-writing campaigns and used the media and the courts ably.

These techniques would be repeated and refined over the next two decades. Jane Jacobs had been a foot-soldier in the battle over Washington Square Park, but she would become a general fighting Robert Moses' attempt to build the Lower Manhattan Expressway during the 1960s. Jacobs ably organized rallies, obtained celebrity support and disrupted meetings of the city's board of estimate. Jacobs was also part of the movement to establish the Greenwich Village Historic Preservation District, which effectively ended any possibility of mega-projects in the area. Such districts are one example of the post-1960 barriers to building and they have spread throughout the country.

Opposition to new projects also became a nationwide phenomenon in the late 1950s and 1960s. In 1956, a "freeway revolt" started in San Francisco against the elevated Embarcadero Freeway. In Boston, activists like Father Paul McManus, community activist Chuck Turner and even engineers like the young Fred Salvucci and James Morey helped organize effective opposition to an inner beltway project. Even in Atlanta, the Morningside/Lenox Park Association was formed in 1965 to combat the construction of Interstate 485.

The 1950s and 1960s were a great epoch of community activism regarding civil rights, the Vietnam War and urban construction projects. In all cases, citizens took action against elected leaders and used techniques of civil disobedience, mass organization and media relations. These disparate movements learned from one another, and effectively produced a form of social capital that was able to impose costs on political leaders. In many cases, the leaders of this movement were well educated, but in other cases, their skills were learned "on the job."

The net result of this growth in social capital is that it became much harder for infrastructure projects to ignore community opposition. Altshuler and Luberoff's (2003) third phase is the natural outcome of this change: projects could only proceed if they effectively ameliorated all of the local residents concerns. Consequently, project costs became higher and projects became more rare. The next section of the paper presents a formal model of this transformation.

\section{Model Setup}

We consider a simple spatial model that consists of three discrete geographic units: the city, the suburbs, and the rest of the country. We consider investment in a transportation system in the city that will benefit both the city and the suburbs, and may generate positive spillovers for the rest of the country too.

\subsection{The Economy}

Each location $l \in\{c, s, r\}$ has a homogeneous population with mass $n_{l}$ and earnings per capita $w_{l} y$, where $w_{l}$ measures relative earnings and $y$ average income. We normalize total 
population to unity, so $\sum_{l} n_{l}=1$ and $\sum_{l} n_{l} w_{l}=1$. Earnings determine the amount of taxes paid and the benefits of transportation.

Each individual takes a number $q_{l}$ of trips using the city's transportation system, with $\min \left\{q_{c}, q_{s}\right\}>q_{r} \geq 0$. This formulation enables us to consider national spillovers from investment in the city, while naturally assuming that the infrastructure is used mostly by local residents. Moreover, we can study both projects like a subway that are used most intensively by city residents $\left(q_{c}>q_{s}\right)$ and others like radial highways that mostly benefit suburbanites instead $\left(q_{s}>q_{c}\right)$. The assumption that $q_{l}$ is an exogenous parameter rather than an endogenous choice considerably simplifies our algebra and enables us to focus most sharply on the political-economy distortion at the core of our analysis. On the other hand, it admittedly sidesteps many interesting aspects of transportation policy, such as network effects and the behavioral response to new projects.

While the roads in our model do get congested, we do not have an intensive driving margin. Consequently, the construction of new roads does not generate new demand that causes excess congestion. This means that our model fails to generate the Downs-Thomson paradox that is empirically verified by Duranton and Turner (2013). Roads, in this model, actually do reduce congestion. If we allowed an intensive driving option, then the benefits of new roads would presumably decline. If roads had fewer benefits, then the downsides of NIMBYism typically would fall too. The costs of NIMBYism would reappear, however, if we also allowed congestion pricing, because that would bring the benefits of new construction back up.

The opportunity cost of time spent in transit is proportional to earnings. Each trip through the city requires time $t$, so the total opportunity cost of travel for a resident of location $l$ equals $\gamma t q_{l} w_{l} y$.

Transportation investment $i$ reduces the time required for each trip in the city according to $t=T(i) G(q)$, where $q=\sum_{l} n_{l} q_{l}$ is the total number of trips through the city, and the functions satisfy $G(q)>0, G^{\prime}(q)>0, T(i)>0, T^{\prime}(i)<0$ and $T^{\prime \prime}(i)>0$ with $\lim _{i \rightarrow 0} T^{\prime}(i)=-\infty$ and $\lim _{i \rightarrow \infty} T^{\prime}(i)=0$. This structure is far from wholly general but it nests natural assumptions about transport spending and congestion. For example, we could specify $t=i^{-\alpha} q^{\alpha+\beta}$, such that time per trip declines isoelastically with investment per trip but rises isoelastically with the total number of trips because of congestion.

On the other hand, investing in infrastructure creates an inconvenience cost for city residents. This cost is proportional to both the amount of spending and the opportunity cost of time, and thus equals ziw $y$. This inconvenience cost can reflect both the sound and disturbance of the construction and the negative externalities from the infrastructure to nearby residents once it is operational, which can include both air pollution and noise. This inconvenience cost can also include the costs of relocation, and even neighborhood demolition. We assume that this term is proportional to wages because many of these costs are time-related, including the disturbed sleep, illness and the inconvenience of moving. We will later allow the inconvenience level $z$ to be reduced at a cost, assuming that the builders can choose to build in ways that create massive relocation of households, like the early Robert Moses projects, or in ways that keep existing neighborhoods largely intact.

The cash cost of investment is partly paid locally by the metropolitan area and partly defrayed through national taxes. We assume that taxes are not distortive but proportional to income. This could be because they are levied in the form of property taxes, or because 
they are income taxes but employment is lumpy: the representative resident of location $l$ works a full-time job that provides net earnings $\left(1-\tau_{l}\right) w_{l} y$, and travel time reduces his leisure, whose opportunity cost $\gamma w_{l} y$ is independent of taxation.

In particular, we assume that a share $\lambda$ of total investment $i$ is financed locally through a uniform metropolitan $\operatorname{tax} \tau_{m}$ on the city and the suburbs. Our definition of income shares implies that aggregate income in the metropolitan area is $\left(n_{c} w_{c}+n_{s} w_{s}\right) y=\left(1-n_{r} w_{r}\right) y$. As a result, we can write the local budget constraint as

$$
\tau_{m}\left(1-n_{r} w_{r}\right) y=\lambda i
$$

where the left-hand side equals local tax revenue and the right-hand side equals the amount of local financing of transportation investment. The remaining share $1-\lambda$ of investment is defrayed through a uniform nationwide $\operatorname{tax} \tau_{r}$. Since national income is $y$, the national budget constraint is

$$
\tau_{r} y=(1-\lambda) i
$$

where the left-hand side equals national tax revenue and the right-hand side equals the amount of national financing of transportation investment.

Assuming quasilinear utility, the welfare of city residents equals:

$$
U_{c}(i)=\left[1-\tau_{m}-\tau_{r}-\gamma T(i) G(q) q_{c}-z i\right] w_{c} y
$$

the welfare of suburbanites equals:

$$
U_{s}(i)=\left[1-\tau_{m}-\tau_{r}-\gamma T(i) G(q) q_{s}\right] w_{s} y
$$

and the welfare of the representative resident of the rest of the country equals:

$$
U_{r}(i)=\left[1-\tau_{r}-\gamma T(i) G(q) q_{r}\right] w_{r} y
$$

\subsection{Electoral Politics}

Transportation investment is chosen by politicians facing electoral incentives. We model policy-making as the outcome of an electoral process with binding platform commitments but imperfectly and heterogeneously informed voters, following Ponzetto (2011) and Glaeser and Ponzetto (2014).

The election is contested by two parties, labelled $D$ and $R$, whose only goal is to win office and which accordingly choose their policy proposals $i_{D}$ and $i_{R}$ to maximize the probability of obtaining a majority of the votes cast. The electorate consists of a measure-one continuum of voters. Following the probabilistic-voting approach (Lindbeck and Weibull 1987), voters' preferences for the competing parties comprise two independent elements. Each resident of location $l$ derives utility $U_{l}(i)$ from the transportation investment enacted by the winner of the election. Moreover, the two parties have fixed characteristics, such as ideology or the personal qualities of party leaders, that cannot be credibly altered with the choice of an electoral platform; and each voter $v$ has individual tastes, respectively $\xi_{v}^{D}$ and $\xi_{v}^{R}$, for these characteristics.

In the standard probabilistic-voting model, parties choose binding policy platforms and all voters perfectly observe them. We relax the assumption of perfect information, and 
instead consider a random process of imperfect information acquisition. Information arrives independently across agents. By the time the election is held, a resident of location $l$ has observed policy proposals with probability $k_{l} \in[0,1]$. With complementary probability $1-k_{l}$ the voter reaches the election completely uninformed, though with rational expectations.

A growing body of literature shows how the level of voter knowledge shapes the provision of infrastructure and political outcomes more generally. Strömberg (2004) documents that there were more New Deal projects in areas that had more radio listeners during the 1930s. Gerber, Karlan and Bergan (2009) show that randomly exposing voters to either left-wing or right-wing newspapers led to increased support for Democratic candidates in 2006. Ferraz and Finan (2008) find that the exposure of corrupt mayors in Brazil led voters to elect new leaders. Björkman and Svensson (2009) train communities to monitor health-care providers and find that this improves health care provision, health care utilization and health outcomes.

Given his information $I_{v}$, voter $v$ votes forms rational beliefs $\left(\tilde{\imath}_{D}, \tilde{\imath}_{R}\right)$ about the policies the two candidates have proposed and would respectively enact if elected. Although each atomistic voter has probability zero of deciding the election with his ballot, we set aside the rational-voter paradox through the conventional assumption that voting is costless, so all agents turn out to vote. As a consequence, a voter's decision is summarized by his preference to support one party over the other. Voter $v$ from location $l$ chooses to support party $R$ if and only if

$$
\mathbb{E}\left[U_{l}\left(\tilde{\imath}_{D}\right) \mid I_{v}\right]+\xi_{v}^{D} \leq \mathbb{E}\left[U_{l}\left(\tilde{\imath}_{R}\right) \mid I_{v}\right]+\xi_{v}^{R}
$$

An individual's relative assessment of the two candidates' non-policy characteristics can be disaggregated into a common and an idiosyncratic component: $\xi_{v}^{D}-\xi_{v}^{R}=\Psi+\psi_{v}$. Both $\Psi$ and $\psi_{v}$ are unobservable to politicians, and independently drawn from common-knowledge probability distributions. The common shock $\Psi$ accounts for the aggregate uncertainty in the electoral outcome. The idiosyncratic shock $\psi_{v}$ provides the intensive margin of political support, and is independent and identically distributed across agents. For the sake of clarity, we assume that $\psi_{v}$ has a uniform distribution with support $[-\bar{\psi}, \bar{\psi}]$ sufficiently wide that each voter's ballot is not perfectly predictable on the basis of policy considerations only. ${ }^{1}$

All residents of each location $l \in\{c, s, r\}$ have an identical utility function $U_{l}(i)$ and identical information-acquisition probabilities $k_{l}$. Since there is a continuum of agents in each location and the arrival of information is independent across agents, these probabilities coincide with the shares of voters from each group that have observed policy proposals. ${ }^{2}$

\section{Policy Formation}

In this section, we discuss the distributive tensions across regions that surround infrastructure investment, and how they are resolved through electoral politics.

\footnotetext{
${ }^{1}$ This assumption simplifies the analytical derivations but hardly involves a loss of generality. In a symmetric pure-strategy Nash equilibrium of the platform-proposal game the policy proposals are independent of the specific distribution of $\psi_{v}$.

${ }^{2}$ The assumption that information arrives independently across agents simplifies our exposition but is not necessary for our analysis. The model is robust to any correlation of information across agents, with $k_{l}$ denoting the expected share of region- $l$ residents that reach the election having observed policy proposals.
} 


\subsection{Preference Conflict}

To simplify notation, let $\Gamma \equiv \gamma G(q)$ denote the cost of congestion. The preferences of the representative resident of each region are a concave function $u_{l}(i)$ with a unique, strictly positive bliss point $i_{l}$, which is implicitly defined by:

$$
\Gamma\left|T^{\prime}\left(i_{l}\right)\right| y q_{l}=1-\lambda+\lambda \frac{1-\mathbf{1}_{l=r}}{1-n_{r} w_{r}}+y z \mathbf{1}_{l=c},
$$

where $\mathbf{1}_{l=r}$ is an indicator variable for the rest of the country and $\mathbf{1}_{l=c}$ for the city center. This condition simply equates marginal benefits for the location on the left-hand side and unit costs for the location on the right-hand side.

The marginal benefits reflect the returns to the investment technology $\left(T^{\prime}\right)$ and thus they are decreasing in the amount of investment. They also reflect amount congestion that infrastructure relieves $(\Gamma)$ and aggregate income $(y)$, which raises the cost of congestion one-to-one. The only region-specific element is the amount of usage per capita $\left(q_{l}\right)$.

Benefits also scale with the relative size of the region's economy $\left(n_{l} w_{l}\right)$, but so do costs. Hence, the right-hand side captures the unit cost of investment per unit of regional income. This cost comprises two components: the direct cash cost, and the inconvenience imposed on city residents. For the share or investment that is financed nationally $(1-\lambda)$, there is a unit cash cost per unit of income. For the share that is financed locally $(\lambda)$, residents of the rest of the country pay no cash cost, but the contributions of residents of the city and its suburbs scales up in inverse proportion to the size of the metropolitan economy relative to the national total $\left(1-n_{r} w_{r}\right)$. Finally, the inconvenience cost falls exclusively on city residents, and it is proportional to income as well as to the inconvenience parameter $(z)$.

The distributive tensions that shape the politics of transportation investment are captured by the comparative statics on the bliss points.

Proposition 1 Each region's desired investment increases with the cost of congestion $\left(\partial i_{l} / \partial \Gamma>\right.$ $0)$, with aggregate income ( $\partial i / \partial y>0)$, and with its own residents' infrastructure usage $\left(\partial i_{l} / \partial q_{l}>0\right)$. The city's desired investment decreases with the inconvenience it causes $\left(\partial i_{c} / \partial z<0\right)$. An increase in local financing reduces the investment desired by local taxpayers but increases the investment desired by outsiders $\left(\partial i_{c} / \partial \lambda<0, \partial i_{s} / \partial \lambda<0\right.$ and $\left.\partial i_{r} / \partial \lambda>0\right)$.

The first results highlights two responses that all citizens qualitatively agree on. If congestion is a more pressing problem, more infrastructure is needed to relieve it. Moreover, the opportunity cost of time spent travelling is proportional to income, so higher incomes increase the benefit of infrastructure investments that reduce travel times. The nuisance costs of construction are also proportional to wages, but since the first order condition weighs a benefit that is wholly proportional to wages against costs that are only partially proportional to wages, the overall impact of wage increases must be to make construction more appealing.

Two other unsurprising sets of comparative statics highlight benefits and costs that only one region internalizes. Infrastructure becomes more appealing when people take more trips: rising numbers of automobile users increased the case for investing in urban expressways and the interstate highway system. Naturally, each region is concerned with its own usage needs: residents are willing to share a higher burden if they expect to use the infrastructure more. 
Higher inconvenience costs naturally mean that infrastructure becomes socially costlier, but this cost is only felt by the city itself.

The final set of results in Proposition 1 show how local support for infrastructure spending depends on the source of tax revenues. Intuitively, every region like more investment the more it can free ride. When local residents are particularly responsible for paying for the infrastructure, then they will want less of it, and if non-metropolitan residents pay for the bulk of the infrastructure then they will want more of it, as long as the nuisance costs are not too high. This can help explain why infrastructure spending became far more popularlocally — after World War II. Since projects were being significantly funded by voters in other cities and states, then local leaders became enthusiastic about large projects. Conversely, greater local financing raises investment demand from the rest of the country, which can enjoy positive spillovers without having to defray construction costs. ${ }^{3}$

We complete our description of distributive conflict by characterizing the ranking of the regions from the most opposed to the most enthusiastic about infrastructure.

Proposition 2 Suppose that residents of the suburbs use infrastructure as much as city residents $\left(q_{s} \geq q_{c}\right)$. Then residents of the suburbs desire strictly more investment than city residents $\left(i_{s}>i_{c}\right)$. Moreover, there are two thresholds for usage spillovers outside the metropolitan area:

$$
\bar{q}_{r}^{c} \equiv \frac{(1-\lambda) q_{c}}{1+\lambda n_{r} w_{r} /\left(1-n_{r} w_{r}\right)+y z}
$$

and

$$
\bar{q}_{r}^{s} \equiv \frac{(1-\lambda) q_{s}}{1+\lambda n_{r} w_{r} /\left(1-n_{r} w_{r}\right)},
$$

with $\bar{q}_{r}^{s}>\bar{q}_{r}^{c}>0$, such that residents of the rest of the country want the least infrastructure if usage spillovers are low $\left(q_{r}<\bar{q}_{r}^{c} \Leftrightarrow i_{s}>i_{c}>i_{r}\right)$, more infrastructure than city residents but less than residents of the suburbs if usage spillovers are intermediate $\left(\bar{q}_{r}^{c}<q_{r}<\bar{q}_{r}^{s} \Leftrightarrow\right.$ $\left.i_{s}>i_{r}>i_{c}\right)$, and the most investment if usage spillovers are high $\left(q_{r}>\bar{q}_{r}^{s} \Leftrightarrow i_{r}>i_{s}>i_{c}\right)$.

City residents are more opposed to construction when income or inconvenience are higher $\left(\partial \bar{q}_{r}^{c} / \partial y<0\right.$ and $\left.\partial \bar{q}_{r}^{c} / \partial z<0\right)$. Residents of the city and the suburbs are more favorable to construction when their own usage is higher $\left(\partial \ln \bar{q}_{r}^{c} / \partial \ln q_{c}=\partial \ln \bar{q}_{r}^{s} / \partial \ln q_{s}=1\right)$ and when federal financing is higher $\left(\partial \bar{q}_{r}^{c} / \partial \lambda<0\right.$ and $\left.\partial \bar{q}_{r}^{s} / \partial \lambda<0\right)$.

Within the metropolitan area, there are two drivers of preference heterogeneity. First, city residents alone suffer the inconvenience of infrastructure investment. Second, residents of the city and the suburbs have different needs for the infrastructure. If suburbanites use infrastructure at least as much as urbanites do $\left(q_{s} \geq q_{c}\right)$, both forces point in the same direction: the suburbs are then unambiguously more gung-ho about construction than the central city. This is also true if the city uses the infrastructure more intensively, so long as inconvenience costs are sufficiently high.

For residents of the rest of the country, the key preference drivers are spillovers $\left(q_{r}\right)$ and federal subsidies $(1-\lambda)$. Intuitively, if funding is fully local, outsiders are the keenest promoters of local infrastructure that generates any positive externalities whatsoever

\footnotetext{
${ }^{3}$ For similar reasons, residents of the metropolitan area are less enthusiastic about investment if the local tax base is relatively small, i.e., if $n_{r} w_{r}$ is large.
} 
$\left(\lim _{\lambda \rightarrow 1} \bar{q}_{r}^{c}=\lim _{\lambda \rightarrow 1} \bar{q}_{r}^{s}=0\right)$. Conversely, if funding is fully national then outsiders and suburbanites face the same calculation, so the most intensive users will be the most enthusiastic supporters of construction $\left(\lim _{\lambda \rightarrow 0} \bar{q}_{r}^{s}=q_{s}\right)$.

Proposition 2 details the more general but equally intuitive taxonomy. Outsiders are even less keen on infrastructure than central-city residents if spillovers and local funding are low while inconvenience and within-city usage are high. Outsiders are even keened on infrastructure than suburbanites if spillovers and local funding are high while suburban usage is low. They are the intermediate constituency for intermediate parameter values. ${ }^{4}$

\subsection{Equilibrium Investment}

Electoral competition with imperfectly informed voters and an intensive margin of political support elicits from both parties the equilibrium policy proposal:

$$
i=\arg \max _{i \geq 0} \sum_{l} k_{l} n_{l} U_{l}(i)
$$

Intuitively, a politician gains support if his policy proposals are more attractive for the voters who learn about them. The intensive margin of political support makes the relationship continuous: a candidate's probability of victory increases smoothly with his platform's appeal to informed voters.

Equilibrium policies aggregate the preferences of different groups, but their weight in politicians' objective function aren't identical, as efficiency maximization would require. Instead, voters' preferences are weighted by their level of information, because so is their response to policy proposals. An uninformed agent would fail to notice a deviation from the expected policy choice, and thus could not react to such a deviation when casting his vote. Politicians optimally choose policy proposals that cater disproportionately to the preferences of those voters who are disproportionately likely to observe them, because only those voters' ballots reflect directly the policy commitments.

The equilibrium policy proposal is characterized by the first-order condition $\sum_{l} k_{l} n_{l} U_{l}^{\prime}(i)=$ 0 . Given the utility functions in Equations 3,4 and 5, we can write out explicitly the equilibrium condition:

$$
\Gamma\left|T^{\prime}(i)\right| y \sum_{l} k_{l} q_{l} n_{l} w_{l}=\sum_{l} k_{l}\left(1-\lambda+\lambda \frac{1-\mathbf{1}_{l=r}}{1-n_{r} w_{r}}\right) n_{l} w_{l}+y z k_{c} n_{c} w_{c} .
$$

The left-hand side describes the political salience of the benefits from infrastructure. The summation on the right-hand side reflects the associated tax burden. The final term reflects the inconvenience costs imposed of city residents.

Equilibrium investment remains responsive to the basic drivers of its efficiency.

Corollary 1 Investment increases with the cost of congestion ( $\partial i / \partial \Gamma>0)$, with aggregate income $(\partial i / \partial y>0)$, and with the number of trips using the system $\left(\partial i / \partial q_{l}>0\right)$. It decreases with the inconvenience it causes to city residents $(\partial i / \partial z<0)$.

\footnotetext{
${ }^{4}$ Residents of the metropolitan area are also more reluctant to support investment when the local tax base is small, so local financing has a higher impact per capita. Thus, $\bar{q}_{r}^{c}$ and $\bar{q}_{r}^{s}$ are both smaller if $n_{r} w_{r}$ is large.
} 
The comparative statics of Corollary 1 are unsurprising and follow directly from Proposition 1. When people take more trips, these trips become more time-consuming, the opportunity cost of time rises, or nuisance costs decline, all citizens demand (weakly) more investment. As a consequence, not only efficient investment but also equilibrium investment rises.

Yet, though the political calculus does reflect the social costs and benefits of transportation investment, it does so only qualitatively. Quantitatively, electoral politics do not correctly internalize all the social impacts of infrastructure spending. As a consequence, equilibrium investment can be too high or too low relative to the optimum.

We define efficient investment $i^{*}$ as the investment level that minimizes the sum of construction and commuting costs, which is equivalent to maximizing social welfare with equal weights for all citizens. We can write out explicitly the optimality condition:

$$
\Gamma\left|T^{\prime}\left(i^{*}\right)\right| y \sum_{l} q_{l} n_{l} w_{l}=\sum_{l}\left(1-\lambda+\lambda \frac{1-\mathbf{1}_{l=r}}{1-n_{r} w_{r}}\right) n_{l} w_{l}+y z n_{c} w_{c} .
$$

This optimality condition and the equilibrium condition in Equation 9 coincide if citizens in all locations are equally informed $\left(k_{c}=k_{s}=k_{r}\right)$. We can then summarize the equilibrium policy distortion as follows.

Proposition 3 In the political equilibrium, investment in transportation is excessive if and only if:

$$
\begin{aligned}
\Omega \equiv \ln \frac{T^{\prime}\left(i^{*}\right)}{T^{\prime}(i)}=\ln & \frac{\sum_{l} k_{l} q_{l} n_{l} w_{l}}{\sum_{l} q_{l} n_{l} w_{l}} \\
& \quad-\ln \frac{(1-\lambda) \sum_{l} k_{l} n_{l} w_{l}+\lambda \sum_{l \neq r} k_{l} n_{l} w_{l} /\left(1-n_{r} w_{r}\right)+y z k_{c} n_{c} w_{c}}{1+y z n_{c} w_{c}}>0 .
\end{aligned}
$$

We measure overinvestment by the ratio of the marginal productivity of investment at the optimum and in equilibrium. This index is appropriate for any neoclassical production function, but in particular for an isoelastic function it would be proportional to the ratio of investment levels themselves: if $T(i)=i^{-\alpha}$ then $\Omega=(1+\alpha)\left(\ln i-\ln i^{*}\right)$. Substantively, overinvestment or underinvestment in infrastructure depends on the geographic spread of information.

The first term equals the share of travel costs incurred by informed voters. This captures political misperception of the marginal benefits of construction due to the covariance between knowledge and infrastructure use. Formally, it is the logarithm of the share of travel costs incurred by informed voters. When all three locations are equally informed, then the first line equals the overall population share of informed voters. When people who use the infrastructure rarely are better informed, then the first line is smaller. When infrastructure users are particularly well informed, then the first line is larger.

The second term equals the share of the unit costs of constructions borne by informed voters. It captures the political misperception of construction costs. As the denominator highlights, each unit of investment has a unit cash cost plus the cost of inconvenience for city residents. Thus, the first addend in the numerator is the share of the total cost that consists of national taxes paid by informed taxpayers. It multiplies the share of federal financing by 
the share of federal taxes paid by informed voters. This is higher than the overall population share of informed voters if richer regions are better informed about the project, and lower if information is higher instead in poorer regions.

The second addend is the share of total costs that consists of local taxes paid by informed voters. This term multiplies the share of the project that is being funded locally and the share of local taxation defrayed by informed taxpayers. When local residents are particularly well informed and they are paying a large share of the total project's costs, then this term is higher than the overall share of informed voters and as a result investment is likely to be too small.

Finally, the third addend is the share of total costs that consists of inconvenience suffered by informed voters. Since only city-dwellers incur these costs, what matters here is their information relative to the population as a whole. When the city-dwellers are ill-informed, as perhaps some urban populations were immediately after World War II, then the tendency will be to ignore the nuisance problems and overbuild. When the city-dwellers are particularly well-informed, as they may well be in the modern era, then nuisance costs will loom particularly large in the political calculus and under-investment will be the larger problem.

We have chosen to model political biases as reflections of knowledge, but of course, political clout can differ across groups for other reasons as well. Urban or suburban voters may be better organized or more likely to be vote or more likely to be marginal voters. Such differences would act just like information in our model, and lead the preferences of the more powerful group to matter more in equilibrium. It is possible, therefore, that the US experienced too much building during the Moses era not because urban voters were uninformed but because they were ill organized. The organizing work by Shirley Hayes and Jane Jacobs can be seen as a shift in the political power of the urbanites. Equivalently, of course, their work can also be seen as spreading information about the project across their own neighborhood.

In our model, voters are uninformed about the policy proposals, not about their costs; but it is also quite possible that they have mistaken beliefs about the costs of policies as well. For example, they may underestimate the congestion that will accompany new roads, or they may overestimate the nuisance created by a new construction project. Such errors would be easy to insert in the model, and if voters overestimated the downsides of nuisance, this would lead to even more underbuilding. If voters underestimated the nuisance costs, this would balance the political forces leading to underinvestment and could even lead to overinvestment relative to the fully informed social optimum.

\section{The Rise of NIMBYism}

We now turn to the history that motivated our model. We consider the dividing line between the era of Moses' overbuilding and modern NIMBYism as reflecting a shift in the information levels of city dwellers. In the immediate post-war period, we assume that the city-dwellers were relatively uninformed. Through efforts like community organizing by Shirley Hayes and Jane Jacobs, information spread. Better organization also meant that city-dwellers become more effective politically.

We capture this evolving pattern of information asymmetry through a simple process 
of information acquisition. All voters receive information about policy proposals from nationwide news sources such as national TV networks. For simplicity, we assume that every voter in every location learns of policy proposals from this channel with the same probability $k_{N} \in[0,1)$.

Residents of the metropolitan area also learn about local policy proposals from local news sources such as city newspapers. To capture the suburbs' early advantage in information and political clout, we assume that suburbanites learn of policy proposals from this channel with probability $k_{L} \in[0,1)$, but central-city residents with probability $\rho k_{L}$ for $\rho \in[0,1)$.

Conversely, residents of the central city naturally have more opportunities and greater incentives to become informed of policy proposals concerning their own neighborhoods. We can summarize all such phenomena by treating community organizations as a preferential source of information that city residents alone have access to, and that informs them about policy proposals with probability $k_{C} \in[0,1)$.

Proposition 4 Information about infrastructure spending is higher within the metropolitan area than outside it $\left(k_{r}<\min \left\{k_{c}, k_{s}\right\}\right)$. It is higher in the city than in the suburbs if and only if community organizations are sufficiently active $\left(k_{c}>k_{s} \Leftrightarrow k_{C}>\bar{k}_{C}\right)$, while local news are not too important and do not favor the suburbs too much $\left(\partial \bar{k}_{C} / \partial k_{L}>0>\partial \bar{k}_{C} / \partial \rho\right)$.

Proposition 4 provides a simple summary of the forces that led to a reversal of fortune in the relative political power of the city and the suburbs. In an earlier period, local newspapers were Americans' leading source of political information, while inner-city communities were poorly organized and carried little political clout. Over subsequent decades, local newspapers declined (Gentzkow 2006) while community organization efforts took off. Both trends have made the central city more powerful and the suburbs less powerful. The rest of the country remains throughout the least influential constituency, since information about local projects is naturally lower outside the affected metropolitan area.

Our next result illustrates the impact of this shift on infrastructure investment.

Proposition 5 There is a threshold $\bar{z} \geq 0$ such that if and only if inconvenience is high enough $(z \geq \bar{z})$ then an increase in city residents' information reduces equilibrium investment $\left(\partial i / \partial k_{c} \leq 0\right)$. Greater information in the city center is more likely to reduce investment when city residents use the infrastructure less and others use it more $\left(\partial \bar{z} / \partial q_{c} \geq 0, \partial \bar{z} / \partial q_{s} \leq 0\right.$ and $\left.\partial \bar{z} / \partial q_{r} \leq 0\right)$ and when income is higher $(\partial \bar{z} / \partial y \leq 0)$.

There are two thresholds $\hat{z} \geq 0$ and $\Xi \geq 0$ such that if and only if inconvenience is high enough $(z>\hat{z})$ and local news are uninformative enough $\left(0<k_{L}<1 / \Xi\right)$ and favor the suburbs enough $(\rho<\Xi)$ then there is overinvestment in the absence of community organization $\left(k_{C}=0 \Rightarrow \Omega>0\right)$ but underinvestment with perfect community organization $\left(k_{C}=1 \Rightarrow \Omega<0\right)$. A switch from over- to underinvestment is more likely when city residents use infrastructure less $\left(\partial \hat{z} / \partial q_{c} \geq 0\right)$, when residents of the suburbs uses it more $\left(\partial \hat{z} / \partial q_{s} \leq 0\right)$ and when income is higher $(\partial \hat{z} / \partial y \leq 0)$.

Suppose residents of the suburbs use infrastructure no less than city residents $\left(q_{s} \geq q_{c}\right)$. Then greater information in the city center is more likely to reduce investment when federal subsidies are lower $(\partial \bar{z} / \partial \lambda \leq 0)$. Moreover, a switch from over- to underinvestment must happen on a path of monotonically declining investment $(\hat{z} \geq \bar{z})$. 
Proposition 5 first gives conditions under which increasing information for city-dwellers will lead to less building. When inconvenience costs are high enough, city residents are the strongest opponents of new construction. This is especially true if they are not also the main users of infrastructure, and typically if federal subsidies are modest.

The second set of conditions characterizes when increasing community organization triggers not merely a monotonic decline in investment but also a shift from over- to underinvestment. Intuitively, this requires analogous but typically more restrictive conditions on inconvenience costs and infrastructure usage. ${ }^{5}$ In addition, it also requires two symmetric bounds on the effectiveness of local news. First, the central city must be sufficiently uninformed to suffer overinvestment in the absence of community organization $(\rho<\Xi)$. Second, the suburbs must not be so informed that their political clout avoids underinvestment even when information in the city center is perfect $\left(k_{L}<1 / \Xi\right){ }^{6}$

During the immediate post-war period, suburban car commuters were richer than most city-dwellers, primarily because owning cars cost money. This income was presumably also associated with more political clout, both because of campaign donations and because of more political knowledge. Consequently, in those days of weak organization of poorer urbanites, there was too much investment.

Gradually, the level of information rose in the city, especially in the richer areas. As we have discussed, the first defeats of Robert Moses were not in the poorer areas of Harlem or Queens, but in the tonier areas of the Upper West Side and Greenwich Village. The techniques developed in those areas then spread and made community organizing common everywhere.

Proposition 5 highlights that central-city information is more likely to reduce investment when inconvenience and income are higher. In general, the Appendix proves that $\partial^{2} \Omega /\left(\partial k_{c} \partial z\right)<0$ and $\partial^{2} \Omega /\left(\partial k_{c} \partial y\right)<0$. This means not only that rising central-city information reduces investment when inconvenience is high enough, but also that rising income reduces investment when city residents are informed enough.

Proposition 6 Overinvestment decreases with aggregate income and with the inconvenience it causes to city residents $(\partial \Omega / \partial z<0$ and $\partial \Omega / \partial y<0)$ if and only if community organization is powerful enough, the suburbs' advantage in learning about policy from local news is low enough, and federal subsidies high enough. Formally:

$$
\frac{k_{C}}{k_{L}}+\rho\left(1-k_{C}\right)>\frac{\left[(1-\lambda)\left(1-n_{r} w_{r}\right)+\lambda\right] n_{s} w_{s}}{(1-\lambda)\left(1-n_{r} w_{r}\right)\left(1-n_{c} w_{c}\right)+\lambda n_{s} w_{s}} .
$$

The proposition emphasizes that once the level of urban information rises sufficiently, then further increases in income will cause the level of investment to fall even further. The condition simply means that the information of central-city residents who suffer inconvenience is greater than the information of the average taxpayer $\left(k_{c}>(1-\lambda) \sum_{l} k_{l} n_{l} w_{l}+\right.$

\footnotetext{
${ }^{5}$ The only difference is that the role of spillovers outside the metropolitan area $\left(q_{r}\right)$ becomes ambiguous. If they are very high while federal subsidies are low, higher information in the metropolitan area induces underinvestment irrespective of community organization - but community organizing makes underinvestment worse.

${ }^{6}$ The first constraint is more likely to bind when federal subsidies and spillovers are low, and the second when they are high: $\partial \Xi / \partial \lambda<0<\partial \Xi / \partial q_{r}$.
} 
$\left.\lambda \sum_{l \neq r} k_{l} n_{l} w_{l} /\left(1-n_{r} w_{r}\right)\right) .{ }^{7}$ Intuitively, this is true if city residents get enough information from community organization $\left(k_{C}\right)$ and from local news $(\rho)$, while local news don't provide too much information to the suburbs $\left(k_{L}\right)$. Federal subsidies $(1-\lambda)$ also make such NIMBYism more likely because they shift the tax burden onto less informed voters outside the metro area. ${ }^{8}$

Rising income means that nuisance costs are higher and this will lead to even less investment, assuming that the urban residents are sufficiently well informed. Consequently, this proposition describes the path of post-war urban America as featuring an increase in information followed by rising incomes.

Proposition 6 also has cross-sectional implications. It suggests that there will be more investment in poorer parts of the city and less in richer areas. It suggests that there will still be overbuilding in poorer metropolitan areas, but not in richer areas.

The social optimum also values the time of the rich more highly. As urbanites become wealthier, the model suggests that it is efficient to reduce the inconveniences that they face. Consequently, some fraction of the trend towards decreasing investment in urban infrastructure can be explained through pure maximization of social welfare. However, in our model, the decrease is too large because the nuisance is so salient to these voters. Political forces cause the downsides of nuisance to be overvalued because it is so visible to a few citizens.

While we chose to focus on transportation rather than residential construction, the two forms of investment are not totally distinct. Historic preservation districts, like the one in Greenwich Village that Jane Jacobs championed, will stop both new highways and new homes. A political process that decides whether to permit new homes will also tend to block building in areas where voters are better informed, assuming that those voters find new construction to be a nuisance. This logic also predicts that new construction will be easier in places where political information is rarer and political organization is weaker. New construction will presumably avoid well educated districts and well educated metropolitan areas. We will also discuss the empirical support for this implication later.

The implications of our model reflect political economy and the disproportionate salience of nuisance. If the city were entirely built by a profit-maximizing developer, these salience effects would decrease or disappear entirely. The developer would care primarily about land values and would set investment levels largely to maximize property values. If developers could pre-commit to future investment levels, then they would internalize the true cost of nuisance, because initial buyers pay less if they anticipate more nuisance. If developers cannot pre-commit, then if anything there would be too much nuisance-causing investment, because they would not internalize the costs experienced by property owners who have already bought.

The US does have cities, like The Woodlands in Texas, that are largely built and operated by private development companies. While there are few systematic studies, these private cities do seem to be more comfortable adding more infrastructure as needed. Typically, governance structures are set up so that existing owners have a voice, but not a veto, and

\footnotetext{
${ }^{7}$ To see that the two conditions coincide, note that the left-hand side of the condition in Proposition 6 can also be written $\left(k_{c}-k_{r}\right) /\left(k_{s}-k_{r}\right)$.

${ }^{8}$ Intuitively, national news $\left(k_{N}\right)$ do not matter because all citizens regardless of their residence are equally likely to receive information from this source.
} 
this means that they are somewhat less empowered than in traditional cities.

\section{Financing}

In this section, we consider how the political economy of transportation investment depends on its financing mechanism, which we take as exogenously given.

\subsection{Federal Subsidies and Overinvestment}

First, our model implies that local financing reduces investment by reducing the ability of well-informed local residents to free-ride on national funding.

Proposition 7 Federal financing increases investment because the rest of the country is less informed about investment proposals than the metropolitan area:

$$
\frac{\partial i}{\partial \lambda}<0 \Leftrightarrow k_{r}<\bar{k}_{m} \equiv \frac{k_{c} n_{c} w_{c}+k_{s} n_{s} w_{s}}{n_{c} w_{c}+n_{s} w_{s}} .
$$

If voter information were symmetric, policy decisions made at the federal level would not depend on the allocation of the tax burden $(\lambda)$. If taxes are disproportionately paid by the metropolitan area $(\lambda>0)$, political competition would merely switch from the extensive margin nationally to an identical intensive margin within the metro area. However, asymmetric information makes this switch non-neutral because voting may respond differently to actual policy proposals in the metropolitan area than in the rest of the country.

Metropolitan voters are naturally happier to finance local investment, whatever its nonpecuniary cost-benefit profile, the more they can get nationwide taxpayers to foot the bill. Proposition 7 gives the condition under which metropolitan voters react to policy proposals more than residents of the rest of the country. Intuitively, this is the case when information is lower in the rest of the country than in the metropolitan area. The threshold $\bar{k}_{m}$ is simply the information over the average local taxpayer: i.e., the mean of information in the city and the suburbs, with weights given by income shares because taxes are proportional to income. The pattern of information acquisition described in Proposition 4 implies that $k_{r} \leq \min \left\{k_{c}, k_{s}\right\} \leq \bar{k}_{m}$, and thus that federal subsidies raise investment.

The distortions induced by federal financing of local projects depend systematically on the size of the local economy relative to the national aggregate. To show this, we can parametrize income shares so that the national economy is $N>1$ times as large as that of the metropolitan area, while the city center represents a share $\kappa \in(0,1)$ of the latter. Formally:

$$
n_{c} w_{c}=\frac{\kappa}{N}, n_{s} w_{s}=\frac{1-\kappa}{N} \text { and } n_{r} w_{r}=1-\frac{1}{N},
$$

for $\kappa \in(0,1)$ and $N>1$. This means that the metropolitan area as a whole represents a share $1 / N$ of the overall economy, and the city center a share $\kappa$ of the economy of the metropolitan area. Then the following result obtains.

Proposition 8 Federal financing of local projects has a greater impact on overinvestment when the economy of the metropolitan area is smaller $\left(\partial^{2} \Omega /(\partial \lambda \partial N)<0\right)$. 
As Proposition 7 already established, a federal funding regime leads to more spending whenever locals are better informed about projects than people outside. The outsiders are presumably less likely to hear coverage of the project, as it will only impact them through their overall tax bill. In the real world, the impact of any area's project on the taxes of the rest of the country is relatively modest. Consequently, federal funding will bias towards more funding because the people who enjoy the benefits are relatively better informed than the people who pay the costs.

Proposition 8 shows that this effect is amplified when the metropolitan area is a smaller share of the national economy, because the residents of the area pay a smaller share of the cost and foist more of those costs onto the relatively uninformed country as a whole. This result predicts that federally funded infrastructure may be particularly likely to show up in smaller towns and lower-density areas that pay a small share of the overall tax bill.

Our model thus provides a micro-founded explanation for a well-known distortion of public spending. Overspending on local public goods tends to rise when the jurisdiction that provides them is larger relative to the locality that benefits from them, an empirical regularity that Weingast, Shepsle and Johnsen (1981) called the Law of $1 / \mathrm{N}$. This pattern is broadly confirmed in the data, but its theoretical grounding has proven less satisfactory (Knight 2006). The prediction emerges from Weingast's (1979) theory of universalism, which assumes that Congress lets members choose spending in their own districts, but not from strategic models of legislative bargaining (Baron and Ferejohn 1989). ${ }^{9}$ In our setting, politicians act strategically, but the Law of $1 / \mathrm{N}$ holds because voters' limited information prevents them from monitoring wasteful overspending outside their region, and thus from punishing it at the polls.

Although our result in Proposition 8 is more general, the Law of $1 / \mathrm{N}$ emerges with particular clarity if we focus on the classic case of public goods with no local downsides and no external spillovers.

Corollary 2 Suppose transportation investment causes no inconvenience $(z=0)$ and generates no spillovers outside the metropolitan area $\left(q_{r}=0\right)$, and that information is homogeneous within the metropolitan area $\left(k_{c}=k_{s}=\bar{k}_{m}\right)$. Then:

$$
\Omega=-\ln \left[1-(1-\lambda)\left(1-\frac{k_{r}}{\bar{k}_{m}}\right)\left(1-\frac{1}{N}\right)\right] .
$$

This exact version of the Law of $1 / \mathrm{N}$ highlights three drivers of distortion. First, overinvestment declines with local financing, which reduces the scope for free-riding. Second, overinvestment declines when outsiders' information draws closer to that of the metropolitan area, reducing political capture. Third, overinvestment declines with the relative size of the city, which induces its residents to internalize a greater share of federal taxation.

\subsection{Optimal Funding}

We have so far been considering the implications of an exogenous funding rule. Now we shift and consider the optimal spending rule, at least from the perspective of minimizing

\footnotetext{
${ }^{9}$ Besley and Coate (2003) define universalism instead as cooperative bargaining. Overspending then emerges as districts non-cooperatively elect representatives that overvalue local public goods.
} 
total costs for transportation, nuisance and infrastructure. As discussed in Proposition 3, the information differences imply that for any given information, spending is unlikely to minimize costs. Yet by choosing the exact spending rule, optimal investment can sometimes induce optimal spending.

As Proposition 9 highlights, the key is to use the rule to balance out the information differences. Denote the information of the average user of infrastructure by

$$
\bar{k}_{q} \equiv \frac{\sum_{l} k_{l} q_{l} n_{l} w_{l}}{\sum_{l} q_{l} n_{l} w_{l}}
$$

and the information of the average national taxpayer by

$$
\bar{k}_{t} \equiv \sum_{l} k_{l} n_{l} w_{l}<\bar{k}_{m}
$$

recalling that by definition the income shares add up to one $\left(\sum_{l} n_{l} w_{l}=1\right)$, and that voters outside the metropolitan area are the least informed about infrastructure projects proposed for it, as shown by Proposition 4.

Proposition 9 There is underinvestment irrespective of federal subsidies if city residents and the average national taxpayer are too informed relative to the average user $\left(\bar{k}_{t}-\bar{k}_{q}+\right.$ $\left.\left(k_{c}-\bar{k}_{q}\right) y z n_{c} w_{c}>0\right)$. There is overinvestment irrespective of federal subsidies if the average user is too informed relative to city residents and the average local taxpayer $\left(\bar{k}_{m}-\right.$ $\left.\bar{k}_{q}+\left(k_{c}-\bar{k}_{q}\right) y z n_{c} w_{c}<0\right)$. If instead information asymmetries between city residents, the average user and average taxpayers are sufficiently balanced that

$$
\bar{k}_{q}-\bar{k}_{t} \geq\left(k_{c}-\bar{k}_{q}\right) y z n_{c} w_{c} \geq \bar{k}_{q}-\bar{k}_{m},
$$

then there is a level $\lambda^{*} \in[0,1]$ of local financing that induces optimal investment.

The optimal amount of local financing is decreasing with income and local inconvenience if and only if city residents are more informed than the average user of infrastructure from outside the city center:

$$
\frac{\partial \lambda^{*}}{\partial y}<0 \Leftrightarrow \frac{\partial \lambda^{*}}{\partial z}<0 \Leftrightarrow k_{c}>\frac{\sum_{l \neq c} k_{l} q_{l} n_{l} w_{l}}{\sum_{l \neq c} q_{l} n_{l} w_{l}} .
$$

Suppose residents of the suburbs use infrastructure no less than city residents $\left(q_{s} \geq q_{c}\right)$. Then the optimal amount of local financing falls with city information $\left(\partial \lambda^{*} / \partial k_{c}<0\right)$ and rises with suburb information $\left(\partial \lambda^{*} / \partial k_{s}>0\right)$. It falls with the information of the rest of the country if and only if the city is more informed than the suburbs $\left(k_{c}>k_{s} \Leftrightarrow \partial \lambda^{*} / \partial k_{r}<0\right)$.

While the proposition holds more generally, it is intuitive to focus on the case in which city-dwellers are better informed about the project than the average user $\left(k_{c}>\bar{k}_{q}\right)$. Then, two intuitive conditions must be satisfied for an optimal cost-sharing rule to induce optimal investment. On the one hand, fully federal financing must induce no less than the optimal investment. This requires users must be more informed on average than national taxpayers $\left(\bar{k}_{q}>\bar{k}_{t}\right)$, so federal subsidies increase support for investment in the metropolitan area without triggering an equally strong opposition to expenditure from the rest of the country. 
Moreover, the level of nuisance cannot be too high, or else forceful local opposition will lead to underinvestment even if all funding is at the federal level. On the other hand, there must be no more than the optimal investment in the absence of any federal funding. This is certainly true if local taxpayers are at least as informed as users $\left(\bar{k}_{q} \leq \bar{k}_{m}\right)$. Otherwise nuisance must be large enough for NIMBYism to compensate the greater political influence of users relative to local taxpayers.

If those conditions are met, then there will exist an optimal share of federal funding that corrects for local underprovision. We suspect that our model may justify a continuing role for federal infrastructure support today, but it probably does not explain why federal funding boomed during the Great Depression and the immediate post-war era. The Great Depression projects were primarily motivated by a desire to reduce unemployment. Eisenhower's support for the highway system was partially military. In both cases, the supporters perceived an external benefit from building that justified federal funding.

Today, however, when local opposition to projects can be quite strident, federal funding may indeed help to balance any tendency towards underprovision generated well-informed local voters. It is worth stressing that the impact of federal funding will be different in smaller and larger communities, and that a federal funding formula that leads to efficient infrastructure in small-town Montana will still lead to underprovision in New York City. As we will discuss later, federal funding will also lead to overspending on mitigation that reduces the nuisance costs of new construction.

Proposition 9 tells us that when city dwellers are better informed than the average noncity user of infrastructure, then the federal funding share that induces optimal investment increases with local income and the nuisance level. The logic of this result is that when city dwellers are particularly well informed, then the nuisance will lead to underspending. Rising levels of income or nuisance harm cause the underinvestment to become more extreme, which must be offset by a larger federal funding share.

If the level of information is higher in the city than in the rest of the country (as it is with the pattern of information acquisition described in Section V), then the optimal level of federal funding falls with suburban information, because within the city the pro-infrastructure suburbanites become more politically powerful. There is less need to provide external support in this case, because the suburbanites are already able to get more infrastructure spending. Finally, the local share needs to be lower when outsiders have better information, because better informed outsiders will typically lead to less support for the infrastructure since they pay the costs but get less of the benefit. ${ }^{10}$

\footnotetext{
${ }^{10}$ Nationwide transparency $\left(k_{r}\right)$ increases political internalization of nationwide spillovers $\left(q_{r}\right)$, but also of the cash cost of investment. The two effects drive spending in opposite directions, and the size of the latter depends on the share of local financing $(\lambda)$. When a first-best financing scheme exists $\left(\lambda^{*} \in[0,1]\right)$ it makes the overall impact unambiguous. If central-city nimbyists are dominant, optimal federal financing is high enough that federal taxes dominate the nationwide debate. Thus, more nationwide information tends to lower spending, so optimal federal financing needs to rise further to preserve optimal investment. Conversely, if suburban builders are dominant, optimal federal financing is low enough that spillovers dominate the nationwide debate. Thus, more nationwide information tends to lower spending and optimal federal financing needs to fall further to avoid excessive inconvenience.
} 


\subsection{Local Decision-Making}

We have so far assumed that decision-making is largely national. This assumption may be appropriate in many more centralized polities, such as the United Kingdom or Japan. However, within the United States, decision-making largely occurs at the state and local level, even with federal funding. Consequently, we now examine how the role for federal funding changes if decisions are made entirely by the locality. In this case, federal funding is really akin to a traditional subsidy and it will only make sense when the locality provides too little infrastructure on its own.

We assume that electoral competition at the local level is identical to competition in national elections, save for the smaller electorate. As a consequence, the local political equilibrium elicits from both parties the equilibrium policy proposal:

$$
i_{L}=\arg \max _{i \geq 0} \sum_{l \neq r} k_{l} n_{l} u_{l}(i)
$$

Let $\lambda_{L}$ denote the share of local financing of locally-decided projects, and by

$$
\chi \equiv \frac{q_{r} n_{r} w_{r}}{\sum_{l} q_{l} n_{l} w_{l}}
$$

the usage externality outside the metropolitan area, measured as the share of the value of trips accounted for by residents of the rest of the country. Then we can characterize the efficiency of local investment on the lines of Proposition 3.

Proposition 10 In a local political equilibrium, investment in transportation is increasing in federal subsidies $\left(\partial i_{L} / \partial \lambda_{L}<0\right)$. Without federal subsidies, local decision-making yields insufficient investment if and only if:

$$
\bar{k}_{q}-\chi k_{r}<\frac{\bar{k}_{m}+y z k_{c} n_{c} w_{c}}{1+y z n_{c} w_{c}} .
$$

The condition in Proposition 10 is a special case of the one in Proposition 3 for $\lambda=1$ and $k_{r}=0$. These parameter values reflect respectively the absence of federal subsidies, and the smaller electorate. Since residents of the rest of the country don't vote for local politicians choosing the level of investment, their preferences drop out of the political objective function, just as they would for federal policy-making if they were completely uninformed about policy proposals.

As a consequence, there are two reasons why local decision-making and local funding lead to under-provision. Most obviously, the locals don't value the travel-time savings for nonlocal residents: the left-hand side of the condition is the share of total trips made by informed local voters. The use of local infrastructure by travellers, including the military, was one justification for the federal funding of the interstate highway system. There can be under provision however even if non-local usage is zero, if city dwellers who use the infrastructure less and suffer the nuisance more are particularly well informed. In that case, the subsidy can potentially undo the underinvestment as long as the nuisance costs are again neither too high nor too low. 
Proposition 11 Local decision-making entails underinvestment irrespective of federal subsidies if city residents and local taxpayers are too informed relative to the average user, usage externalities are too high, and the metropolitan area comprises too large a share of the economy $\left(\left(1-n_{r} w_{r}\right) \bar{k}_{m}+\chi k_{r}-\bar{k}_{q}+\left(k_{c}+\chi k_{r}-\bar{k}_{q}\right) y z n_{c} w_{c}>0\right)$. Local decisionmaking entails overinvestment irrespective of federal subsidies if the average user is too informed relative to city residents and local taxpayers, and usage externalities are too low $\left(\bar{k}_{m}+\chi k_{r}-\bar{k}_{q}+\left(k_{c}+\chi k_{r}-\bar{k}_{q}\right) y z n_{c} w_{c}<0\right)$. If instead usage externalities and information asymmetries between city residents, the average user and local taxpayers are sufficiently balanced that

$$
\bar{k}_{q}-\chi k_{r}-\left(1-n_{r} w_{r}\right) \bar{k}_{m} \geq\left(k_{c}+\chi k_{r}-\bar{k}_{q}\right) y z n_{c} w_{c} \geq \bar{k}_{q}-\chi k_{r}-\bar{k}_{m},
$$

then there is a level $\lambda_{L}^{*} \in[0,1]$ of local financing that induces optimal investment.

The optimal amount of local financing is decreasing with income and local inconvenience if and only if city residents are sufficiently informed:

$$
\frac{\partial \lambda_{L}^{*}}{\partial y}<0 \Leftrightarrow \frac{\partial \lambda_{L}^{*}}{\partial z}<0 \Leftrightarrow k_{c}\left(1+\frac{q_{r} n_{r} w_{r}}{q_{s} n_{s} w_{s}}\right)>k_{s} .
$$

Suppose that residents of the suburbs use infrastructure as much as city residents $\left(q_{s} \geq\right.$ $\left.q_{c}\right)$. Then the optimal amount of local financing falls with city information $\left.\partial \lambda_{L}^{*} / \partial k_{c}<0\right)$ and rises with suburb information $\left(\partial \lambda^{*} / \partial k_{s}>0\right)$.

If first-best investment can be achieved both with federal and with local decision-making, then the optimal degree of local financing is greater with local decision-making if and only if residents of the city are more informed than residents of the suburbs $\left(k_{c}>k_{s} \Leftrightarrow \lambda_{L}^{*}>\lambda^{*}\right)$.

These results mirror directly those for federal policy, because the local political equilibrium coincides with the limit case of the national political equilibrium when there is no information outside the metropolitan area $\left(k_{r}=0\right)$, as we already discussed comparing Propositions 10 and 3.

When investment is decided at the local level, the optimal degree of federal financing is unambiguously more likely to rise with income and local inconvenience $\left(\partial \lambda^{*} / \partial y<0 \Rightarrow\right.$ $\left.\partial \lambda_{L}^{*} / \partial y<0\right)$. Intuitively, local decision-making eliminates any internalization of positive spillovers. As a result, it requires more aggressive subsidies on the financing side to counterbalance the rise of nimbyism.

The other comparative statics are equally intuitive. The local political equilibrium is purely a tug-of-war between the suburbs and the central city. For plausible parameter values, the former promote and the latter oppose building. Thus, when their balance of power shifts optimality requires a compensating shift in federal construction subsidies.

Again, the final result is arguably the most interesting. Our model does not unambiguously imply that greater local financing should accompany local decision-making. This prescription might superficially seem to follow immediately from the Law of $1 / \mathrm{N}$, but it is truly valid only when outsiders are motivated mostly by taxation. On the contrary, federal subsidies should logically be higher when decision-making is local and the main ensuing distortion is a failure to internalize external spillovers. Our model implies that the two cases can be distinguished by a very simple criterion: the balance of power in local government between pro-building suburbs and anti-building city residents. 
We have considered so far the case in which both federal and local decision-making can achieve the socially optimal investment given the ideal financing scheme. We can also characterize which system is more likely to enable reaching the first best. recall that both usage and knowledge of infrastructure are greater for all residents of the metropolitan area than those of the rest of the country $\left(q_{r}<\min \left\{q_{c}, q_{s}\right\}\right.$ and $\left.k_{r}<\min \left\{k_{c}, k_{s}\right\}\right)$

Proposition 12 Unless the suburbs have a small information advantage that is narrowly compensated by usage externalities $\left(k_{s} / k_{c} \notin\left[1,1+q_{r} n_{r} w_{r} /\left(q_{s} n_{s} w_{s}\right)\right]\right)$, with optimal financing local decision-making can attain the first best for intermediate values of nuisance $\left(z \in Z_{L}\right)$, but federal decision-making only for a subset of those values $\left(z \in Z_{F} \subseteq Z_{L}\right)$.

In general, local decision-making is better suited to fine-tuning via federal co-payments than federal decision-making is via local funding mandates. In both cases, the first best can be implemented so long as inconvenience $(z)$ isn't too extreme. The feasible sets are intervals (e.g., $\left.Z_{L}=\left[\underline{z}_{L}, \bar{z}_{L}\right]\right)$, though they may also be empty. The key result in Proposition 12 is that, when either the city of the suburbs have a clear upper hand, local decision-making can cope with a larger set of values than federal decision-making (in fact, $Z_{L}$ is strictly larger than $Z_{F}$ unless it is empty). This condition would be immediately assured if there were no usage externalities outside the metropolitan area $\left(q_{r}=0\right)$.

The greater flexibility of local decision-making is most intuitive when the political equilibrium within the metropolitan area favors city residents concerned with inconvenience $\left(k_{c}>k_{s}>k_{r}\right)$. Then NIMBYism is best fought by federal subsidies when non-local voters have no chance of opposing their largesse. Conversely, if the local political equilibrium decisively favors pro-construction suburbs, their tendency to overbuild is best fought by forcing them to fund all projects locally, while not allowing non-local residents to support investment they don't pay for but derive positive spillovers from. ${ }^{11}$

Finally, we can recognize that optimal financing is difficult to fine tune, and consider the comparison of federal and local decision-making when their respective degrees of local financing are exogenously given.

Proposition 13 Federal decision-making yields higher investment than local decision-making if and only if

$$
\frac{k_{r} q_{r} n_{r} w_{r}}{\sum_{l \neq r} k_{l} q_{l} n_{l} w_{l}}>\frac{(1-\lambda) k_{r} n_{r} w_{r}+\left(\lambda-\lambda_{L}\right) n_{r} w_{r} \bar{k}_{m}}{\left[1-\left(1-\lambda_{L}\right) n_{r} w_{r}\right] \bar{k}_{m}+y z k_{c} n_{c} w_{c}} .
$$

The left-hand side of the condition reflects changes in the way politics internalize the benefits of investment. Formally, it equals the ratio of trips taken by informed outsiders to trips taken by informed local residents. The right-hand side reflects changes in the way politics internalize the costs of investment. Again, the denominator is simply the total cost born by informed residents of the metropolitan area in a purely local scheme. The numerator reflects the national taxes paid by informed outsiders for federally decided policy, but also

\footnotetext{
${ }^{11}$ The only ambiguous case is when the suburbs are only slightly more informed than the central city, while external positive spillovers are sizeable: $1<k_{s} / k_{c}<1+q_{r} s_{r} /\left(q_{s} s_{s}\right)$. Then it is still possible for local decision-making to attain the optimum while federal decision-making cannot. But the reverse also becomes a possibility: internalizing spillovers outside the metro area may be the best chance of preventing overbuilding when inconvenience costs are high.
} 
the change in taxes paid by informed local residents as a consequence of different funding rules.

Intuitively, federal policy is more likely to raise investment if there are greater national spillovers $\left(q_{r}\right)$, greater local inconvenience $(z)$ or higher income $(y)$ and more local financing of local policy choices $\left(\lambda_{L}\right)$. If information is higher inside than outside the metropolitan area $\left(\bar{k}_{m}>k_{r}\right)$, then federal policy is more likely to raise investment when it is accompanied by less local financing $(\lambda)$.

\subsection{User Fees}

In this section, we allow for fee financing, which Brueckner (2015) shows can lead to optimal transportation investment even in the presence of spillovers across jurisdictions. User fee financing, in the form of tolls, is relatively rare for urban roads but more common for intercity highways. De Borger and Proost (2012) provide a political economy model showing why a majority of voters might oppose congestion pricing because of uncertainty, even if a majority of voters would benefit from its introduction.

Let a share $v$ of total investment be financed by user fees, and the remainder with a metropolitan tax for a share $(1-v) \lambda$ and a nationwide tax for a share $(1-v)(1-\lambda)$. Then the welfare of city residents equals

$$
U_{c}(i)=\left(1-\tau_{m}-\tau_{r}\right) w_{c} y-\left[\phi+\gamma T(i) G(q) w_{c} y\right] q_{c}-z i w_{c} y,
$$

the welfare of suburbanites equals

$$
U_{s}(i)=\left(1-\tau_{m}-\tau_{r}\right) w_{s} y-\left[\phi+\gamma T(i) G(q) w_{s} y\right] q_{s},
$$

and the welfare of the representative resident of the rest of the country equals

$$
U_{r}(i)=\left(1-\tau_{r}\right) w_{r} y-\left[\phi+\gamma T(i) G(q) w_{r} y\right] q_{r}
$$

while the budget constraint implies a user fee

$$
\phi \sum_{l} n_{l} q_{l}=v i
$$

and taxes

$$
\tau_{m}\left(1-n_{r} w_{r}\right) y=(1-v) \lambda i \text { and } \tau_{r} y=(1-v)(1-\lambda) i .
$$

Federal policy entails an equilibrium amount of overinvestment equal to:

$$
\begin{aligned}
\Omega=\ln & \frac{\sum_{l} k_{l} q_{l} n_{l} w_{l}}{\sum_{l} q_{l} n_{l} w_{l}} \\
& \quad-\ln \frac{v \sum_{l} k_{l} q_{l} n_{l} /\left(\sum_{l} q_{l} n_{l}\right)+(1-v)\left[\lambda \bar{k}_{m}+(1-\lambda) \sum_{l} k_{l} n_{l} w_{l}\right]+y z k_{c} n_{c} w_{c}}{1+y z n_{c} w_{c}} .
\end{aligned}
$$

The key difference between user fees and taxes is that the former reflect usage and the latter income. Thus, neither properly reflects the value of infrastructure, which increases with both usage and income - in our simple specification, exactly with their product. Denote by

$$
\bar{k}_{\phi} \equiv \frac{\sum_{l} k_{l} q_{l} n_{l}}{\sum_{l} q_{l} n_{l}}
$$


the information of the average payer of user fees. Notice that this is defined differently from the information of the average user $\bar{k}_{q}$ because only the latter reflects the value of trips and thus income.

Proposition 14 User fees increase investment ( $\partial i / \partial v>0)$ if and only if:

$$
\bar{k}_{\phi} \leq \lambda \bar{k}_{m}+(1-\lambda) \bar{k}_{t}
$$

Both user fees and income taxes introduce no distortions in our model, so changing the composition of the tax burden does not affect its efficiency. As a result, the only channel through which financing determines the level of investment is visibility. Investment is higher in equilibrium if it is financed more opaquely, with costs falling on uninformed taxpayers who won't vote against costly projects.

The condition in Proposition 14 simply characterizes when user fees are less visible than taxes. The left hand side is the share of trips taken (and thus fees paid) by informed voters, while the right-hand side is the share of income taxes paid by informed voters.

At the federal level, user fees can be helpful to fine-tune optimal investment when taxbased subsidies do not suffice. Recall from Proposition 4 that information is higher on average in the metropolitan area than in the whole country $\left(\bar{k}_{m}>k_{r}\right)$.

Proposition 15 If $\bar{k}_{\phi}<k_{r}$ user fees can increase investment when it is insufficient even with fully federal funding. If $\bar{k}_{\phi}>\bar{k}_{m}$ user fees can reduce investment when it is excessive even without federal subsidies.

Any level of investment that can be supported as a political equilibrium can be supported with a combination of the most transparent and the most opaque financing mechanism. As a consequence, user fees can raise efficiency if their visibility is extreme. If the share paid by informed voters is even lower for user fees than for federal taxes, they can helpfully reduce underinvestment when city residents oppose even projects that are fully subsidized by federal taxes, because of their local inconvenience costs. If the share paid by informed voters is even higher for user fees than for local taxes, they can helpfully reduce overinvestment when suburbanites impose too much inconvenience on city residents even in the absence of any federal subsidies.

The same logic applies to local decisions. However, in the context of local policy it also becomes interesting to study how user fees can help when the metropolitan area is unable to secure federal subsidies.

Proposition 16 Suppose investment is decided locally without federal subsidies $\left(\lambda_{L}=1\right)$. If national spillovers are high enough $\left(q_{r}>\bar{q}_{r}\right)$, equilibrium investment is insufficient if it is financed entirely through taxes, and rises with the share financed through user fees $\left(v_{L}=0 \Rightarrow \Omega_{L}<0\right.$ and $\left.\partial i_{L} / \partial v_{L}>0\right)$.

The threshold is increasing (decreasing) with inconvenience and income if information is higher (lower) in the suburbs than the city center $\left(k_{s}>k_{c} \Rightarrow \partial \bar{q}_{r} / \partial z \geq 0\right.$ and $\partial \bar{q}_{r} / \partial y \geq 0$, while $k_{s}<k_{c} \Rightarrow \partial \bar{q}_{r} / \partial z \leq 0$ and $\left.\partial \bar{q}_{r} / \partial y \leq 0\right)$.

If residents of the suburbs use infrastructure as much as city residents $\left(q_{s} \geq q_{c}\right)$ and do not earn much higher wages $\left(w_{s} / w_{c} \leq q_{s} / q_{c}\right)$ then the threshold is increasing in the information of the suburbs and increasing in the information of the city center $\left(\partial \bar{q}_{r} / \partial k_{s} \geq 0 \geq \partial \bar{q}_{r} / \partial k_{c}\right)$. 
Intuitively, user fees provide a way for the metropolitan area to capture some of the value of national externalities $\left(q_{r}\right)$. If these are large enough, local taxes induce underinvestment but user fees can relieve it. The balance of power between the city center and the suburbs determines if user fees become more or less useful as income and inconvenience costs rise. When central city residents are better informed and more politically influential, rising income triggers disproportionate opposition to construction. Then it becomes more likely that reliance on user fees is necessary to relieve underinvestment.

The last result shows that a similar effect operates if the city center gains political power at the expense of the suburbs. Then user fees also become more desirable, provided two realistic conditions are satisfied. First, as usual, suburban usage (or inconvenience costs) must be high enough to ensure that suburbs support construction more than the city center. Second, the suburbs cannot be so much richer than the city that their declining information tends to make income taxes more opaque than user fees.

\section{Nuisance Mitigation}

We now focus on the endogenous choice of nuisance. For simplicity, we assume that the cost of reducing nuisance is proportional to the size of the project and equals $i C(z)$, where the function $C(z)$ satisfies $C(z)>0, C^{\prime}(z)<0$ and $C^{\prime \prime}(z)>0$ with $\lim _{z \rightarrow 0} C^{\prime}(z)=-\infty$ and $\lim _{z \rightarrow \infty} C^{\prime}(z)=0$. Thus the total losses from nuisance will be $i\left[z n_{c} w_{c} y+C(z)\right]$, and for any given project size $i$ the first-order condition for efficiency maximization is:

$$
\left|C^{\prime}\left(z^{*}\right)\right|=n_{c} w_{c} y
$$

which implies that it is socially desirable to reduce nuisance as people get richer $\left(\partial z^{*} / \partial y<0\right)$. Likewise, efficient nuisance mitigation is also greater when the city is a larger share of the national economy, i.e., if $n_{c} w_{c}$ is large.

The first-order condition for nuisance mitigation in the national political equilibrium is:

$$
\left|C^{\prime}(z)\right|=\frac{k_{c}}{\lambda \bar{k}_{m}+(1-\lambda) \bar{k}_{t}} n_{c} w_{c} y
$$

Recalling that the rest of the country is less informed than the metropolitan area about infrastructure spending, including spending on nuisance mitigation, this equilibrium condition implies a straightforward characterization of equilibrium nuisance mitigation.

Proposition 17 Nuisance mitigation increases with aggregate income $(\partial z / \partial y<0)$, with federal financing $(\partial z / \partial \lambda>0)$ and with city residents' information $\left(\partial z / \partial k_{c}<0\right)$, while it decreases with the information of residents of the suburbs $\left(\partial z / \partial k_{s}>0\right)$ and of the rest of the country $\left(\partial z / \partial k_{r}>0\right)$.

There is a level $\lambda_{z}^{*} \in[0,1]$ of local financing that induces optimal nuisance mitigation if and if the suburbs are sufficiently more informed than the city center and pay a sufficiently small fraction of national taxes:

$$
\frac{n_{s} w_{s}}{n_{s} w_{s}+n_{r} w_{r}} \leq \frac{k_{c}-k_{r}}{k_{s}-k_{r}} \leq 1
$$


The optimal amount of local financing rises with city information $\left(\partial \lambda_{z}^{*} / \partial k_{c}>0\right)$ and falls with the information of the suburbs $\left(\partial \lambda_{z}^{*} / \partial k_{s}<0\right)$ and of the rest of the country $\left(k_{c}<k_{s} \Leftrightarrow\right.$ $\left.\partial \lambda_{z}^{*} / \partial k_{r}<0\right)$.

This proposition makes several points. First, spending on nuisance mitigation is a simple tug of war between the city center, which receives all its benefits but pays only a fraction of the costs, and the other locations, which pay some of the costs but receive no benefits. Second, federal subsidies weaken opposition to nuisance mitigation by shifting its costs onto less informed residents of the rest of the country. Third, as in Proposition 9, this last property can in principle be exploited to fine-tune the level of nuisance mitigation by adjusting federal subsidies.

If educated people have a higher opportunity cost of time, then it is socially optimal to spend more on abatement in more educated communities. However, because abatement and nuisance are particularly salient, there will be too much abatement in a political equilibrium relative to a social optimum. Moreover, the level of excessive abatement will also increase with the level of education, because education increases political awareness and political clout as well as the cost of nuisance.

Intuitively, the optimal amount of federal subsidies declines with the information of the pro-mitigation city center and rises with the information of the anti-mitigation suburbs. If the city center is more informed than the suburbs, there is over-mitigation even with no federal subsidies: efficiency would require mitigation to be financed by the central city alone and not also by the suburbs. Conversely, if the suburbs' information advantage is too large and they pay too large a share of national taxes, mitigation is insufficient even with fully federal financing.

As in Proposition 6, the term $\left(k_{c}-k_{r}\right) /\left(k_{s}-k_{r}\right)$ could identically be written $k_{C} / k_{L}+$ $\rho\left(1-k_{C}\right)$ in light of our microfoundation of voter information. Thus, the efficient level of federal subsidies falls with community organization $\left(\partial \lambda_{z}^{*} / \partial k_{C}>0\right)$ and rises with the informativeness of local news $\left(\partial \lambda_{z}^{*} / \partial k_{L}<0\right)$ and with suburbs' advantage in learning from them $\left(\partial \lambda_{z}^{*} / \partial \rho>0\right)$, while it is independent of national news $\left(k_{N}\right)$.

A comparison of Propositions 9 and 17 highlights the crucial tension associated with federal subsidies as an instrument to fine-tune efficient investment. The response to shifts in the information and political influence of different regions is exactly opposite for the optimal financing of infrastructure on the one hand and mitigation on the other.

We now focus on this tension by considering simultaneously investment in transportation infrastructure and nuisance mitigation. We assume that individuals are either totally aware of the project, and therefore know both the direct costs of constructions and those of nuisance mitigation, or they are totally unaware of the project and its costs. We also assume that the tax bill is common, so it is impossible to offer federal subsidies for investment but not nuisance mitigation, or vice-versa.

Then equilibrium policy is described jointly by Equation 24 and by the first-order condition for politically optimal construction:

$$
\Gamma\left|T^{\prime}(i)\right| y \sum_{l} k_{l} q_{l} n_{l} w_{l}=\left[\lambda \bar{k}_{m}+(1-\lambda) \bar{k}_{t}\right][1+C(z)]+y z k_{c} n_{c} w_{c},
$$

which generalizes Equation 9 for the case of endogenous mitigation. 
Assuming for the sake of tractability that

$$
C(z)=\Phi\left(\frac{\zeta}{z}\right)^{\zeta} \text { for } \Phi>0 \text { and } \zeta>0
$$

we can establish the following result.

Proposition 18 Suppose that usage is higher in the suburbs than the rest of the country $\left(q_{s} \geq q_{r}\right)$. Then any increase in federal subsidies increases investment in both construction and mitigation $(\partial z / \partial \lambda>0>\partial i / \partial \lambda)$. Optimal federal subsidies can induce simultaneously efficient investment in construction and efficient investment in mitigation only when the information advantage of the suburbs relative to the city center compensates exactly their share of national taxation:

$$
\frac{k_{c}-k_{r}}{k_{s}-k_{r}}=\frac{q_{s} n_{s} w_{s}}{q_{s} n_{s} w_{s}+q_{r} n_{r} w_{r}} .
$$

If city residents are any less informed, then federal subsidies induce at least overinvestment in construction or underinvestment in mitigation $\left(z \geq z^{*} \Rightarrow i>i^{*}\right)$. If city residents are any more informed, then federal subsidies induce at least underinvestment in construction or overinvestment in mitigation $\left(i \geq i^{*} \Rightarrow z>z^{*}\right)$.

Intuitively, it is generically impossible to fine-tune the efficiency of two investment decisions with a single subsidy. Proposition 18 formalizes this intuition. Any increase in federal subsidies induces higher spending on both construction and mitigation. In both cases, the metropolitan area gets something it desires at the expense of unaware taxpayers in the rest of the country. However, in the case of construction, the suburbs are the primary beneficiaries. In the case of mitigation, instead, all benefits accrue to the city center.

As a consequence, it takes a knife-edge coincidence for the optimum $\left(i^{*}, z^{*}\right)$ to be implementable through undifferentiated federal subsidies. Intuitively, if there are no spillovers $\left(q_{r}=0\right)$ the requirement is that information should be perfectly homogeneous within the metropolitan area. Then purely local financing immediately implements the first best, since local politicians perfectly internalize all benefits and all costs - there are no externalities on either side, and the distribution between city center and suburbs is irrelevant when their political influence is identical. If there are positive spillovers $\left(q_{r}>0\right)$, then efficient construction requires federal subsidies. Then, however, inefficient overinvestment in mitigation can be avoided only if information is lower in the city than in the suburbs, and first-best efficiency requires the difference in political clout to balance spillovers exactly.

Generically, instead, the best that federal subsidies can achieve is overinvestment in one dimension and underinvestment on the other - although it is naturally possible to have over-

or underinvestment across the board. When information in the city center is too low, the tendency is to overbuild and undermitigate. When information in the city center is too high, there is instead underbuilding with excessive expenditure of mitigation.

\section{Discussion}

Our model was motivated by the revolt against mega-projects during the 1960 and the subsequent emergence of more sensitive and expensive projects, like the Big Dig (Altshuler and 
Luberoff 2003). Our model explains these trends as the result of the increasing political awareness and income of urbanites. As political organizers, like Shirley Hayes and Jane Jacobs, spread information about the downsides of mega-projects, the number of these projects fell and spending on abatement increased.

Our model also offers ancillary predictions. We hope that more serious empirical tests of these predictions will follow in subsequent work, but here we provide a brief discussion of some of the model's predictions. We focus on cross-sectional implications, which will be easier to test than purely time-series predictions. Throughout our discussion, we will associate political awareness and engagement with education, which is far more readily measurable than actual political knowledge. Galston (2001) discusses the strong cross-sectional link between years of schooling and both political knowledge and activity. Milligan, Moretti and Oreopoulous (2004) show that increases in education generated by compulsory schooling laws also seem to increase political engagement.

\subsection{Building in Greenfields: Nuisance Increasingly Deters Infra- structure}

The model predicts that as the urban population becomes more politically engaged, projects will increasingly be stopped because they are a nuisance to local residents. The converse of this result is that more projects will occur in places were they do not create a nuisance. Consequently, the model predicts that we should expect to see construction targeted towards areas with fewer people.

We can test this implication with data on county-level spending during the Great Recession. The American Recovery and Reinvestment Act (ARRA) directed a large flow of federal funds to states in order to build and rebuild infrastructure. The flow of funds to states followed the Highway Trust Fund formula, but states had discretion about where to spend the money. The ARRA spending is particularly attractive, because the geographic location of all projects is well documented. Garin (2016) provides an analysis of this spending at the county level, and he has provided the graphs that we display here.

The increasing importance of nuisance suggests that this spending should have gone disproportionately to lower density areas. We test that implication by comparing density levels and per capita spending across counties. Figure 1 shows the relationship, controlling for state fixed effects. Looking within state is important, because the funding formula favored low density states.

As the figure shows, per capita spending averaged over $\$ 200$ at lower density levels and less than $\$ 50$ in the highest-density areas. There are many potential explanations for this relationship. Perhaps, it was easier to find shovel-ready projects in lower-density areas. Perhaps, these areas had more senior representation in state legislatures. Yet the negative relationship fails to reject the view that spending has been targeted to places that are less likely to complain about the nuisances associated with new construction.

One consequence of this relationship is that transportation spending went disproportionately to places that have initially shorter commutes. Figure 2 shows the relationship across counties between average commute times, based on the share of the population with a commute time over 30 minutes in the 2000 Census, and ARRA spending per capita. Places 


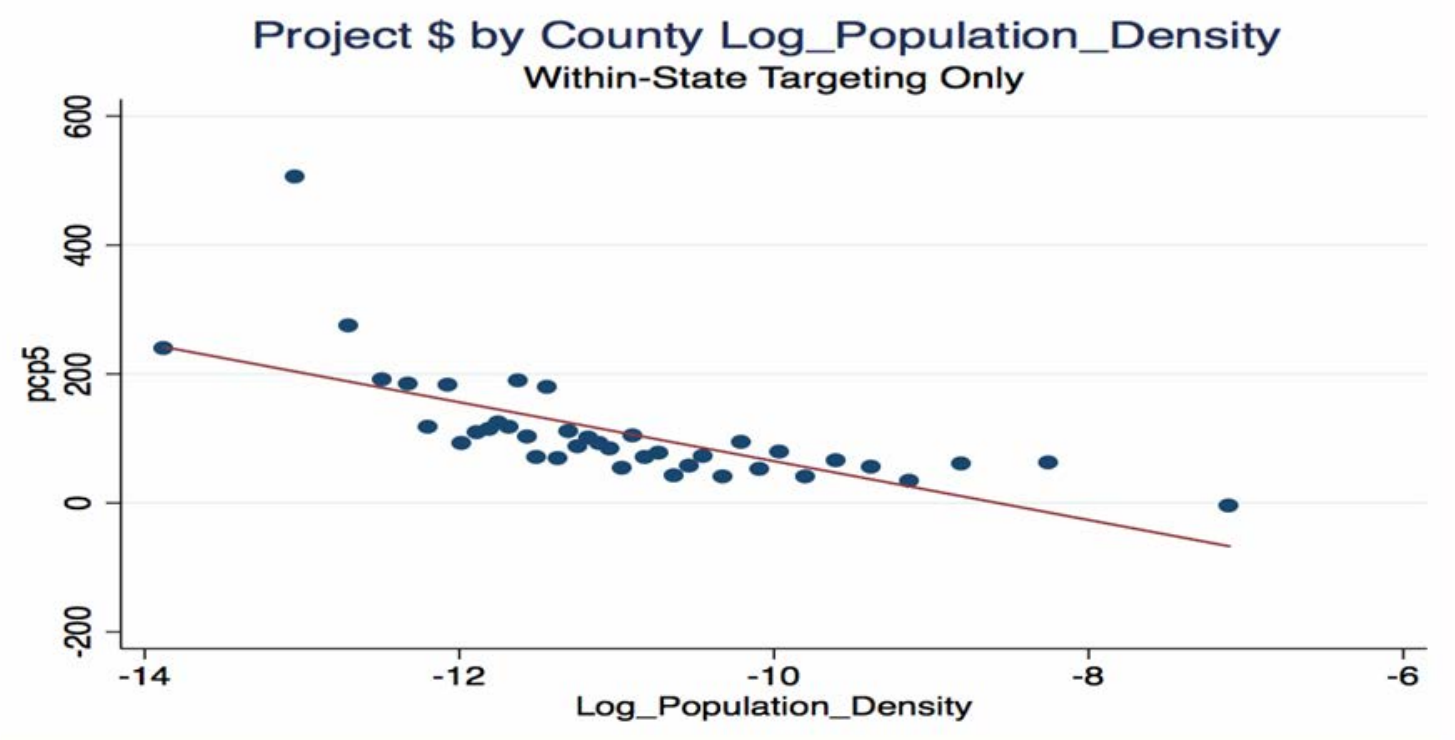

Figure 1: Population Density and ARRA Spending

with low densities typically have shorter commutes, and so the tendency to spend more in lower-density areas means that there was more spending in places with initially shorter commutes.

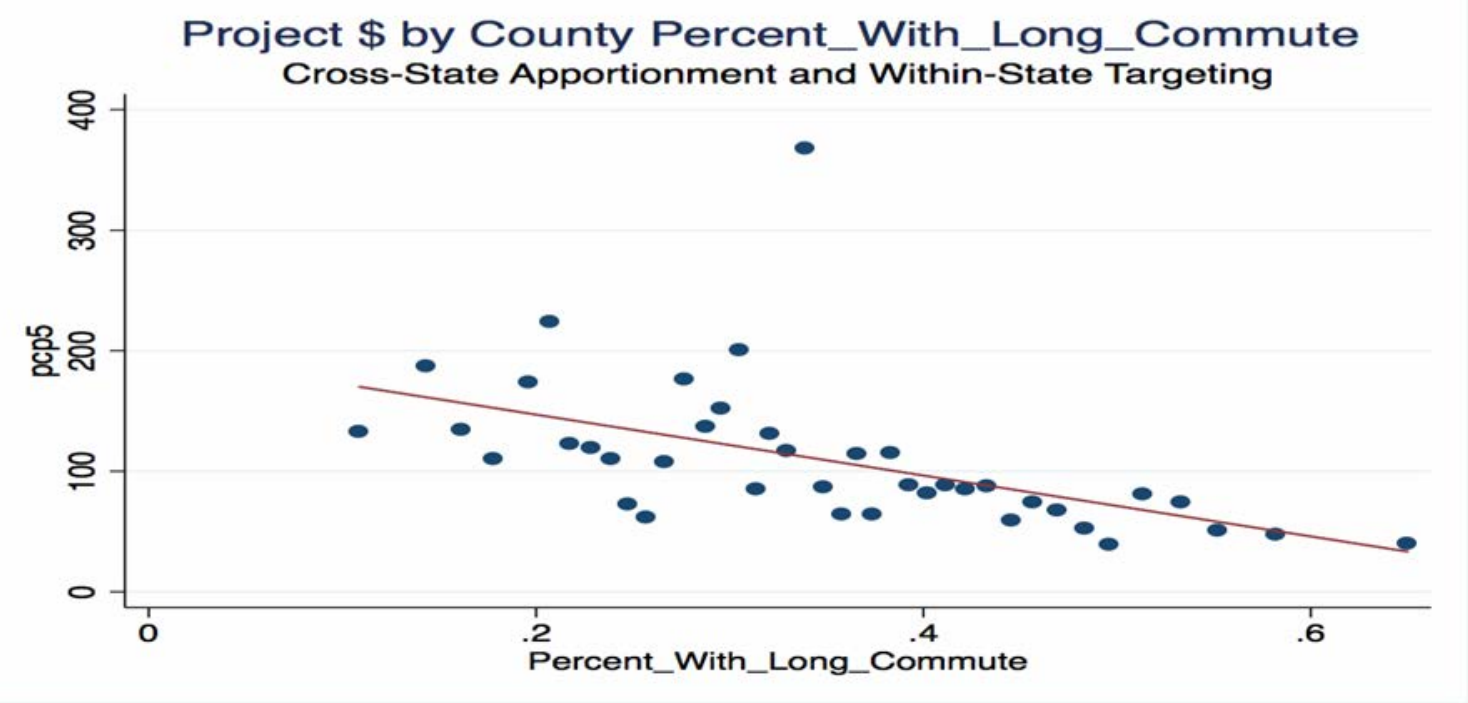

Figure 2: Commute Time and ARRA Spending

This figure does not imply that spending is socially suboptimal. It is possible that the marginal impact of a dollar on commute times was actually higher in lower density areas, perhaps because of the high cost of urban infrastructure. Still, one explanation for why the ARRA spending went to lower density places with shorter commutes is that these areas had fewer abutters who might complain. 
The Anderson Memorial Bridge that connects Cambridge with Boston provides a concrete example of the difficulties in dealing with neighbors in a well-educated, dense environment. The bridge took one year to build in 1915, but over eight years to rebuild a century later. The promise of federal funding partially motivated the 2008 Massachusetts act to finance the bridge reconstruction. Four years were spent in public discussions and planning. A vast number of neighbors contributed to the lengthy delay, including preservation advocates, who ensured that the bridge use special bricks imported from Maine, to cycling enthusiasts, to representatives of river conservancy. Four more years were spent in the construction itself. The vocal and educated community's objections ensured that the bridge would be finished long after the recession that initially motivated the rebuilding was over.

Is this cross-section indicative of a larger trend? Between 1980 and 2014, urban lane miles have increased by 92 percent within the United States, while rural lane miles have actually declined. Certainly, highway lane miles have increased in urban areas over the last 40 years. Yet urban can also mean places that are quite low-density, and the number of urban lane miles can also increase because previously rural areas have become urban. Hopefully, future work will test whether per capita infrastructure spending has more broadly been targeted away from contentious cities.

\subsection{Education and Declining Infrastructure Investment}

A second implication of our analysis is that education should particularly deter large projects, since educated residents are more likely to be both richer and politically engaged. While our model focused on transportation infrastructure, the same logic holds towards permitting significant construction projects. Consequently, we will also discuss the literature on education and barriers to home-building.

Parker et al. (2012) examine proximity to roads across the US population. They find that education and especially income are negatively correlated with proximity to major roads. For example, 27 percent of high school dropouts have more than one major road within 300 meters, while 19 percent of respondents with more than a higher school degree have more than one road within 300 meters. Boehmer et al. (2013) similarly found that 4.1 percent of poorer households lived within 150 meters of a major highway, as opposed to 3.5 percent of the non-poor population.

Yet these results may not tell us about the location of new infrastructure. Infrastructure might be built without regard to area education, but then less educated people could sort into areas that are close to infrastructure because of low rents. Been (1994) highlights this distinction in her work on locally undesirable land uses, and shows that some of the correlation between race or poverty and waste treatment plants represents trends that followed the plant, not initial site location. One prominent exception is that mini-incinerators in Houston were located disproportionately in minority neighborhoods. Hamilton (1995) also finds that waste treatment plant expansions were more common in ZIP codes that were less educated and poorer.

While there have long been claims that road-builders targeted lower-income or less educated neighborhoods, we are not aware of academic research that seriously assesses that hypothesis. The best available evidence comes from Brinkman and Lin (2016), who show that highways were built in areas that otherwise had negative trends. As less educated places 
have done relatively poorly over the past 50 years, this may mean that highways were sited in less educated areas. Yet we hope that future research will be able to more fully test this implication of our model.

The link between education and land use restrictions has been more clearly established. The Wharton Residential Land Use Regulation Index measures the difficulty of building in different parts of the country based on surveys of local land use professionals. Gyourko, Saiz and Summers (2008) report that in the least regulated quarter of metropolitan areas, 23.6 percent of adults have college degrees. In the most regulated quarter of metropolitan areas, 35.4 percent of adults have college degrees.

Within Greater Boston, Glaeser and Ward (2009) examine the distribution of minimum lot sizes and other barriers to building. They find that places with larger average lot sizes are better educated and that education in 1970 correlates with the adoption of more stringent building regulations since that date. These results are compatible with the view that educated people either dislike the nuisance of building more, or are more effective at deterring new construction, perhaps because they are more politically aware.

Another related test of the model is eminent domain, which has often been used as part of mega-project assembly. The model predicts that eminent domain usage will be less common in educated areas, and that compensation is likely to be more generous when more politically aware people are subject to takings. Munch (1976) found that Chicago over-compensated high value properties and under-compensated low value properties after eminent domain takings, which is again compatible with the view that the more educated residents received better treatment. Chang (2010) examines takings in New York, and shows that they occurred disproportionately in the less educated boroughs of the city.

\subsection{Abatement, Cost, and High Human Capital}

Altshuler and Luberoff (2003) describe the emergence of a third epoch of mega-projects in which construction is far more expensive because developers try hard to reduce the costs to local residents. For example, the Big Dig in Boston was done without using eminent domain to take any homes (commercial properties were taken). The Big Dig was also a fabulously expensive piece of infrastructure, perhaps because such steps were taken to avoid local harm.

While there is a lengthy largely engineering literature on how to abate the local nuisances created by roads (e.g., Van Geelen 2012), we know of no literature measuring the extent of investment in road nuisance mitigation across space. There is no clear empirical definition of abatement, which can range from avoiding eminent domain takings to building walls to surround roads. Our model makes the clear prediction that such abatement investments should increase with the level of education, but it is hard to test that prediction without measures of abatement.

In the absence of abatement data, we will provide suggestive evidence here on the link between education and road costs. The Reason Foundation provides annual data on state disbursement per highway mile across US states (Hartgen and Fields 2016). These costs are just the state's spending, using both local and federal sources, per state-controlled highway mile. We cannot be certain that higher costs reflect more effort on abatement, but our model does predict that more education should lead to higher spending because of abatement.

We test that implication by looking across states at the correlation between the share of 
the population with college degrees, which is taken from the 2012 Statistical Abstract of the US, and the logarithm of disbursement per highway mile. We take the logarithm of costs because the cost variable is skewed strongly to the right. New Jersey is a particularly outlier, although its costs have been disputed.

The estimated regression shown in Figure 3 is:

$$
\log (\text { Costs })=\underset{(.55)}{9.42}+\underset{(.02)}{.096} \text { Share with College Degrees. }
$$

The $R^{2}$ is .32 .

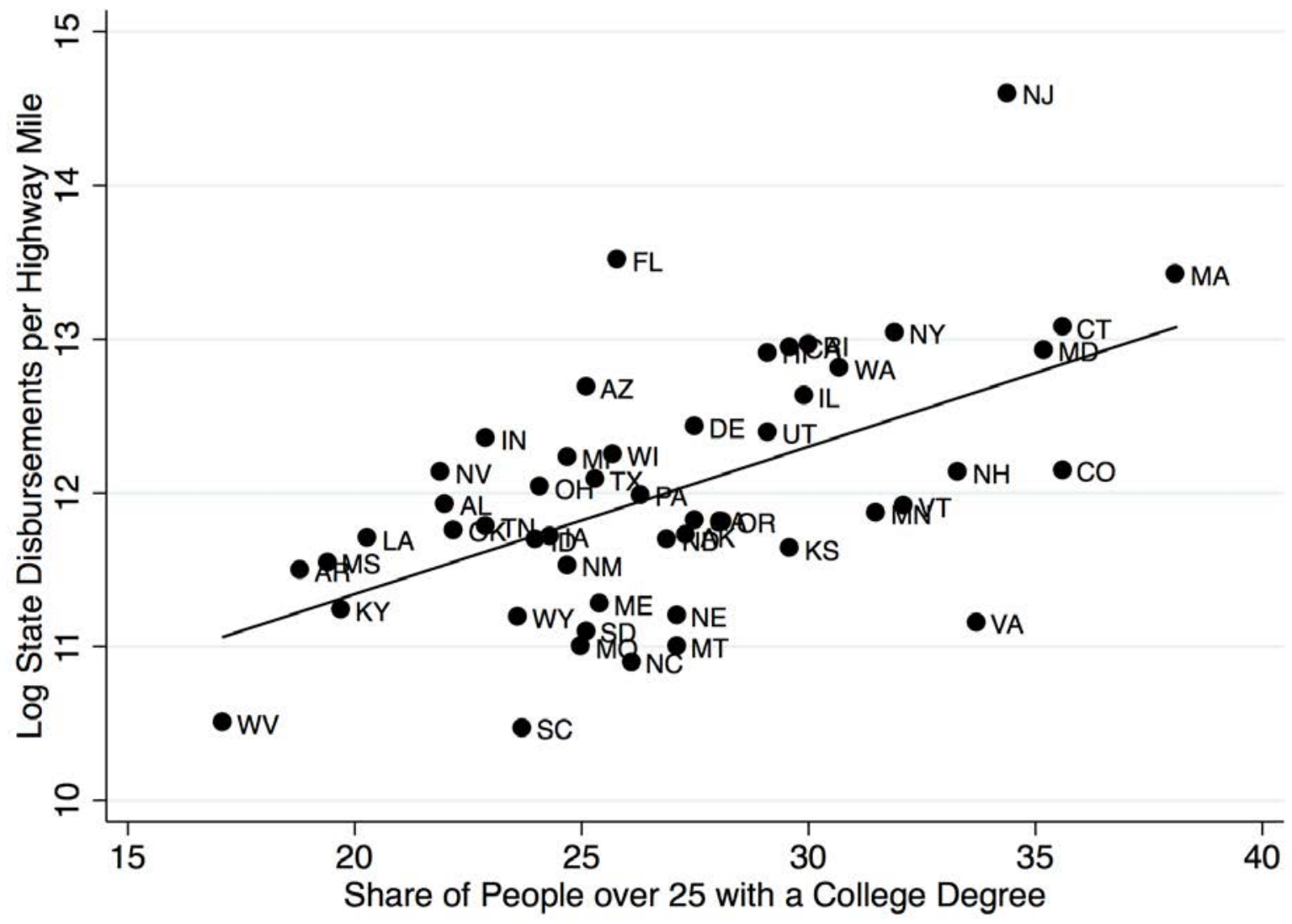

Figure 3: Education and Spending per Highway Mile

The relationship is strong statistically and large in magnitude. As the share of the population with a college degree increases 4.7 percent (one standard deviation), spending per mile increases by 57 percent. This is an extremely large effect, which dwarfs the relationship between education and the cost of labor.

There may be many different factors involved in this empirical relationship. The more educated areas may have denser cities where maintaining roads are more difficult, for example. Yet it is also possible that this relationship reflects more investments in reducing the downsides of transportation, which is the mechanism that our model suggests should link education and transportation costs. We view this relationship as purely suggestive, and 
we again hope that future work will fully investigate this issue, ideally with better data on abatement spending itself.

\subsection{Local vs. National Spending and Control in the US and UK}

Finally, our model yields predictions about local versus national control over spending. We predicted that national control will yield higher spending for cities that experience more non-resident infrastructure use. Local control will yield higher spending for cities with few non-resident visits. This implication does appear to be borne out in a comparison of the US and the UK

The UK and the US provide a reasonable comparison of centralized vs. local decisionmaking. In the UK, transportation, like many public services, is largely determined by the national government. Local governments are relatively weak, and Parliament generally determines where infrastructure investment will occur. In the US, as we already discussed, the federal government grants funds to states and then the states determine where spending will occur.

The Associated Press has prepared data on per capita highway spending by state for 2013. Highway spending is about two-thirds of national transportation infrastructure spending, so on average it would be appropriate to increase the total spending amounts by fifty percent. The lowest per capita highway spending is $\$ 268$ per capita in Georgia. The highest spending is $\$ 1,479$ per capita in Delaware.

There does not appear to be any tendency to provide extra funding for places with more visits from outsiders. For example, Washington, D.C., lies in the middle of this list with $\$ 665$ dollars per capita. The states of New York and Florida both contain massive tourist destinations. They spent $\$ 621$ and $\$ 487$ per capita respectively, although New York's expenditures need to be boosted to include the sizable investment in rail. New York's Metropolitan Transit Agency has a $\$ 15$ billion budget, or $\$ 750$ per resident of the State, although less than ten percent of that is provided by government subsidies.

Since the UK is centralized and since London receives vastly more domestic visitors than any other place in the country, our model predicts that London will receive more spending than any US cities, but that spending elsewhere in the UK will be less than in the US.

UK statistics are somewhat difficult to interpret because of the large private role in funding infrastructure. When private and public spending is combined, the disparities between London and the rest of the country appear to be enormous. For example, Berry, Hunt and White (2015) report infrastructure spending of $£ 5,305$ per head in London, which is well above any state in the US, and spending only $£ 413$ per head in the Northeast of England, which is below much of the US, when we adjust spending upwards to take account of non-highway spending in America.

Cox and Davies (2013) provide per capita spending on projects, which combined private and public spending. In that case, spending ranged from over $£ 2,500$ per capita in London to under $£ 10$ per head in the Northeast. Even purely public spending shows a substantial divergence, with more than $£ 800$ per capita in London and less than $£ 300$ elsewhere. These figures again suggest that London is receiving more infrastructure support than its US counterparts, while other parts of the US are spending less. 
The centralized UK system appears to favor London. The US system does not seem to favor either New York or Washington, DC. Centralized decision-making does indeed seem to favor the one place with a large number of outside visitors. Local decision-making appears to lead to relatively flat spending, with if anything a bias towards places that are well endowed with US senators per capita.

This discussion is again meant to point towards more serious empirical research. Our model predicts that centralization will lead towards more spending in places that have more outside visitors and less spending elsewhere. We believe that a more comprehensive comparison of US and EU spending patterns could provide a better test of that hypothesis.

\section{Conclusion}

In this paper, we have presented a political economy model of transportation investments that emphasizes inattention and nuisance. In the model, two rival inefficiencies battle to determine whether investment is too large or too little. The inattention of national voters to spending in other jurisdictions leads to over-spending. Voters are more likely to be aware of the benefits of local spending than the costs of spending elsewhere. In the extreme, this produces Weingast's Law of $1 / \mathrm{N}$ in which jurisdictions spend as if the project cost were only a fraction of the true costs equal to their share of the total national budget.

But in transportation, local nuisance provides a countervailing force. The downsides of new infrastructure to local residents are even more salient than the benefits to the potential users of infrastructure. Consequently, those costs become particularly important to politicians. When local voters are particularly well-informed relative to potential beneficiaries, then NIMBYism results and promising projects are shut down because of the downsides to local residents.

This model can explain the arc of mega-project history identified by Altshuler and Luberoff (2003). In the New Deal and after World War II, the federal government was funding infrastructure and many urban residents were relatively less well educated, and consequently less well-informed about local development. They were also less well organized. Consequently, America experienced a great wave of urban infrastructure development.

Starting in the mid-1950s and then through the Freeway Revolts of the 1960s, urbanites became better educated and better organized. Their suffering consequently became more important to politicians and development fell. Altshuler and Luberoff's (2003) third period of infrastructure came about when expensive federally-funded abatement was used to mitigate the downsides of new development, just as our model suggests.

Our model also implies that without abatement, the right level of federal funding can be used to offset local opposition to new growth. When the balance between the two forces is perfect, then efficient infrastructure investment results. There are several caveats to this optimistic prediction. First, infrastructure spending grants in the US are formally lump-sum, not matching grants. Theoretically, lump-sum grants do not impact the incentives to build. In reality, the funds are often matched with local spending and, therefore, they may indeed act in practice as they do in the model.

More problematically, the US uses a common fund allotment formula across states, and it is extremely unlikely that the right formula for New York City is also the right formula for 
Montana. The model predicts that if the same matching rule is used everywhere, then there will be too much spending in places where nuisances are low and too little spending where nuisances are high. This prediction seems to be born out by recent infrastructure spending supported by the American Recovery and Reinvestment Act. States tended to allocate dollars much more generously on a per capita basis to counties with lower population density.

We ended the paper by discussing other empirical implications of the model. The model predicts that education will strongly predict the location of nuisance-creating investment. While there have long been allegations that builders, like Robert Moses, put infrastructure in lower human capital areas, the evidence supporting this claim is slim. Poorer people are more likely to live near highways, but it is not clear whether this reflects highway location choices or subsequent migration decisions. Brinkman and Lin (2016) provides some of the first systematic evidence on this question and their work seems to support the hypothesis that highways were targeted towards less successful areas.

Our model also suggested that abatement spending will be higher when infrastructure is built near educated areas. We have no direct measures of abatement spending, but we do find that more educated states spend far more per mile of highway which is an implication of the model. We hope that future research will test this hypothesis more thoroughly.

We also hope that future research will examine the impact of centralized decision-making on the location of transportation spending. Our model predicted that centralization will increase spending in areas which receive a lot of outside visitors and decrease spending elsewhere. This prediction appears to be supported by a comparison of the decentralized US and the centralized UK which spends significantly in London, its largest market for domestic visitors, and less elsewhere.

We end this paper by noting that the political economy of transportation is important but understudied. Inattention and local nuisance are too important factors in transportation, but they are far from the only important aspects of this hugely important sector of the economy. We hope that future research will provide a large body of research on this important topic. 


\section{A Appendix}

\section{A.1. Proof of Propositions 1 and 2}

From Equation 7, the comparative statics on $i_{l}$ are immediate. Moreover, residents of the suburbs desire more investment than residents of the city center $\left(i_{s}>i_{c}\right)$ if and only if:

$$
y z>\left(q_{c}-q_{s}\right)\left(1+\frac{\lambda n_{r} w_{r}}{1-n_{r} w_{r}}\right),
$$

which is satisfied for all $q_{s} \geq q_{c}$. Residents of the rest of the country desire more investment than residents of the city center $\left(i_{r}>i_{c}\right)$ if and only if $q_{r}>\bar{q}_{r}^{c}$ as defined in Proposition 2. Residents of the rest of the country desire more investment than residents of the suburbs $\left(i_{r}>i_{s}\right)$ if and only if $q_{r}>\bar{q}_{r}^{s}$ as defined in Proposition 2. The comparative statics on $\bar{q}_{r}^{c}$ and $\bar{q}_{r}^{s}$ are immediate.

\section{A.2. Proof of Corollary 1 and Propositions 3, 10 and 13}

$$
\mathbb{E}\left[U_{l}\left(\tilde{\imath}_{D}\right) \mid I_{v}\right]+\xi_{v}^{D} \leq \mathbb{E}\left[U_{l}\left(\tilde{\imath}_{R}\right) \mid I_{v}\right]+\xi_{v}^{R} .
$$

Given the realization of the common shock $\Psi$, the fraction of residents of location $l$ who vote for party $R$ equals

$$
s_{l}^{R}=\frac{1}{2}+\frac{1}{2 \bar{\psi}}\left\{k_{l}\left[U_{l}\left(i_{R}\right)-U_{l}\left(i_{D}\right)\right]+\left(1-k_{l}\right)\left[\mathbb{E} U_{l}\left(\tilde{l}_{R}\right)-\mathbb{E} U_{l}\left(\tilde{l}_{D}\right)\right]-\Psi\right\} .
$$

Thus the realization of $\Psi$ determines the number of ballots cast for each candidate: party $R$ receives more votes than party $D$ if and only if

$$
\Psi<\sum_{l} n_{l}\left\{k_{l}\left[U_{l}\left(i_{R}\right)-U_{l}\left(i_{D}\right)\right]+\left(1-k_{l}\right)\left[\mathbb{E} U_{l}\left(\tilde{\imath}_{R}\right)-\mathbb{E} U_{l}\left(\tilde{\imath}_{D}\right)\right]\right\}
$$

For any distribution of the unobservable common shock $\Psi$, party $R$ seeks to maximize the

right-hand side, and party $D$ to minimize it. This leads both parties to solve the same problem:

$$
\max _{i} \sum_{l} n_{l} k_{l} U_{l}\left(i_{R}\right) .
$$

This immediately implies Equation 9, the comparative statics in Corollary 1, and the measure of overinvestment in Proposition 3. Local decision-making coincides with the limit case $k_{r}=0$, which yields immediately Propositions 10 and 13 .

\section{A.3. Proof of Proposition 4}

The share of informed voters in the city center is

$$
k_{c}=1-\left(1-k_{N}\right)\left(1-\rho k_{L}\right)\left(1-k_{C}\right) \text {, }
$$

in the suburbs it is

$$
k_{s}=1-\left(1-k_{N}\right)\left(1-k_{L}\right)
$$


and in the rest of the country it is

$$
k_{r}=k_{N} .
$$

Thus, $k_{c}>k_{s}$ if and only if

$$
k_{C}>\bar{k}_{C} \equiv \frac{(1-\rho) k_{L}}{1-\rho k_{L}}
$$

such that

$$
\frac{\partial \bar{k}_{C}}{\partial k_{L}}=\frac{1-\rho}{\left(1-\rho k_{L}\right)^{2}}>0>\frac{\partial \bar{k}_{C}}{\partial \rho}=-\frac{k_{L}\left(1-k_{L}\right)}{\left(1-\rho k_{L}\right)^{2}} .
$$

\section{A.4. Proof of Proposition 5}

From Proposition 3:

$$
\begin{aligned}
\frac{\partial \Omega}{\partial k_{c}} & =n_{c} w_{c} \\
& \times\left[\frac{q_{c}}{\sum_{l} k_{l} q_{l} n_{l} w_{l}}-\frac{1-\lambda+\lambda /\left(1-n_{r} w_{r}\right)+y z}{(1-\lambda) \sum_{l} k_{l} n_{l} w_{l}+\lambda \sum_{l \neq r} k_{l} n_{l} w_{l} /\left(1-n_{r} w_{r}\right)+y z k_{c} n_{c} w_{c}}\right],
\end{aligned}
$$

such that

$$
\begin{aligned}
\frac{1}{y} \frac{\partial^{2} \Omega}{\partial k_{c} \partial z}=\frac{1}{z} \frac{\partial^{2} \Omega}{\partial k_{c} \partial y}= & \\
& \quad-\frac{\left\{\left[1-\lambda+\lambda /\left(1-n_{r} w_{r}\right)\right] k_{s} n_{s} w_{s}+(1-\lambda) k_{r} n_{r} w_{r}\right\} n_{c} w_{c}}{\left[(1-\lambda) \sum_{l} k_{l} n_{l} w_{l}+\lambda \sum_{l \neq r} k_{l} n_{l} w_{l} /\left(1-n_{r} w_{r}\right)+y z k_{c} n_{c} w_{c}\right]^{2}}<0
\end{aligned}
$$

and that $\partial \Omega / \partial k_{c} \leq 0 \Leftrightarrow \partial i / \partial k_{c} \leq 0$ if and only if $z \geq \bar{z} \equiv \max \{0, \tilde{z}\}$ for

$$
\tilde{z} \equiv \frac{(1-\lambda) \sum_{l} k_{l}\left(q_{c}-q_{l}\right) n_{l} w_{l}-\lambda\left[k_{s}\left(q_{s}-q_{c}\right) n_{s} w_{s}+k_{r} q_{r} n_{r} w_{r}\right] /\left(1-n_{r} w_{r}\right)}{y \sum_{l \neq c} k_{l} q_{l} n_{l} w_{l}},
$$

such that $\partial \bar{z} / \partial q_{c} \geq 0, \partial \bar{z} / \partial q_{s} \leq 0, \partial \bar{z} / \partial q_{r} \leq 0$ and $\partial \bar{z} / \partial y \leq 0$, while

$$
\frac{\partial \tilde{z}}{\partial \lambda}=-\frac{n_{r} w_{r}}{1-n_{r} w_{r}} \frac{k_{s}\left(q_{s}-q_{c}\right) n_{s} w_{s}+k_{r}\left[q_{c}\left(1-n_{r} w_{r}\right)+q_{r} n_{r} w_{r}\right]}{y \sum_{l \neq c} k_{l} q_{l} n_{l} w_{l}} .
$$

There is overinvestment $(\Omega>0)$ if and only if

$$
\begin{aligned}
& \left(k_{s}-k_{r}\right) n_{s} w_{s}\left[\left(1+y z n_{c} w_{c}\right) q_{s}-\left(1-\lambda+\frac{\lambda}{1-n_{r} w_{r}}\right) \sum_{l} q_{l} n_{l} w_{l}\right] \\
& >\left(k_{c}-k_{r}\right) n_{c} w_{c}\left[\left(1-\lambda+\frac{\lambda}{1-n_{r} w_{r}}\right) \sum_{l} q_{l} n_{l} w_{l}-q_{c}+y z \sum_{l \neq c} q_{l} n_{l} w_{l}\right],
\end{aligned}
$$

namely if and only if

$$
\begin{aligned}
\frac{n_{s} w_{s}}{n_{c} w_{c}} & {\left[\left(1+y z n_{c} w_{c}\right) q_{s}-\left(1-\lambda+\frac{\lambda}{1-n_{r} w_{r}}\right) \sum_{l} q_{l} n_{l} w_{l}\right] } \\
> & {\left[\frac{k_{C}}{k_{L}}+\rho\left(1-k_{C}\right)\right]\left[\left(1-\lambda+\frac{\lambda}{1-n_{r} w_{r}}\right) \sum_{l} q_{l} n_{l} w_{l}-q_{c}+y z \sum_{l \neq c} q_{l} n_{l} w_{l}\right] . }
\end{aligned}
$$


Thus, there is overinvestment for $k_{C}=0$ but underinvestment for $k_{C}=1$ if and only if

$$
z>\tilde{z}_{1} \equiv \frac{(1-\lambda) \sum_{l}\left(q_{c}-q_{l}\right) n_{l} w_{l}-\lambda\left[\left(q_{s}-q_{c}\right) n_{s} w_{s}+q_{r} n_{r} w_{r}\right] /\left(1-n_{r} w_{r}\right)}{y \sum_{l \neq c} q_{l} n_{l} w_{l}}
$$

and

$$
z>\tilde{z}_{2} \equiv \frac{\lambda\left[q_{r} n_{r} w_{r}-\left(q_{s}-q_{c}\right) n_{c} w_{c}\right] /\left(1-n_{r} w_{r}\right)-(1-\lambda) \sum_{l}\left(q_{s}-q_{l}\right) n_{l} w_{l}}{y q_{s} n_{c} w_{c}}
$$

and

$$
\rho<\Xi \equiv \frac{n_{s} w_{s}}{n_{c} w_{c}} \frac{\left(1+y z n_{c} w_{c}\right) q_{s}-\left[1+\lambda n_{r} w_{r} /\left(1-n_{r} w_{r}\right)\right] \sum_{l} q_{l} n_{l} w_{l}}{\left[1+\lambda n_{r} w_{r} /\left(1-n_{r} w_{r}\right)\right] \sum_{l} q_{l} n_{l} w_{l}-q_{c}+y z \sum_{l \neq c} q_{l} n_{l} w_{l}}<\frac{1}{k_{L}},
$$

such that $\partial \Xi / \partial \lambda<0<\partial \Xi / \partial q_{r}$.

Let $\hat{z} \equiv \max \left\{0, \tilde{z}_{1}, \tilde{z}_{2}\right\}$. Then $\partial \hat{z} / \partial q_{c}>0, \partial \hat{z} / \partial q_{s} \leq 0$ and $\partial \hat{z} / \partial y \leq 0$. Moreover, $\tilde{z}_{1}=\tilde{z} \Leftrightarrow k_{s}=k_{r}$ and thus $\tilde{z}_{1}>\tilde{z}$ for all $k_{s}>k_{r}$ if $q_{s} \geq q_{c}$, which implies $\partial \tilde{z} / \partial k_{s}<0$.

\section{A.5. Proof of Proposition 6}

From Proposition 3:

$$
\begin{aligned}
& \frac{1}{y} \frac{\partial \Omega}{\partial z}=\frac{1}{z} \frac{\partial \Omega}{\partial y} \\
& =n_{c} w_{c}\left[\frac{1}{1+y z n_{c} w_{c}}-\frac{k_{c}}{(1-\lambda) \sum_{l} k_{l} n_{l} w_{l}+\lambda \sum_{l \neq r} k_{l} n_{l} w_{l} /\left(1-n_{r} w_{r}\right)+y z k_{c} n_{c} w_{c}}\right]
\end{aligned}
$$

and thus $\partial \Omega / \partial z<0 \Leftrightarrow \partial \Omega / \partial y<0$ if and only if

$$
k_{c}-k_{r}>\left(k_{s}-k_{r}\right) \frac{\left[(1-\lambda)\left(1-n_{r} w_{r}\right)+\lambda\right] n_{s} w_{s}}{(1-\lambda)\left(1-n_{r} w_{r}\right)\left(1-n_{c} w_{c}\right)+\lambda n_{s} w_{s}},
$$

namely if and only if

$$
\frac{k_{C}}{k_{L}}+\rho\left(1-k_{C}\right)>\frac{\left[(1-\lambda)\left(1-n_{r} w_{r}\right)+\lambda\right] n_{s} w_{s}}{(1-\lambda)\left(1-n_{r} w_{r}\right)\left(1-n_{c} w_{c}\right)+\lambda n_{s} w_{s}},
$$

such that the derivative of the right-hand side with respect to $\lambda$ equals

$$
\frac{n_{s} w_{s} n_{r} w_{r}\left(1-n_{r} w_{r}\right)}{\left[(1-\lambda)\left(1-n_{r} w_{r}\right)\left(1-n_{c} w_{c}\right)+\lambda n_{s} w_{s}\right]^{2}}>0 .
$$

\section{A.6. Proof of Proposition 7}

From Equation 9, the implicit-function theorem yields:

$$
\frac{\partial i}{\partial \lambda}=\frac{\sum_{l} k_{l}\left(\mathbf{1}_{l=r}-n_{r} w_{r}\right) n_{l} w_{l}}{\Gamma T^{\prime \prime}(i) y\left(1-n_{r} w_{r}\right) \sum_{l} k_{l} q_{l} n_{l} w_{l}} .
$$




\section{A.7. Proof of Proposition 8}

From Proposition 3:

$$
\frac{\partial \Omega}{\partial \lambda}=\frac{\sum_{l} k_{l}\left(\mathbf{1}_{l=r}-n_{r} w_{r}\right) n_{l} w_{l}}{\sum_{l} k_{l}\left[\frac{1}{N}-\lambda\left(\mathbf{1}_{l=r}-n_{r} w_{r}\right)\right] n_{l} w_{l}+y z k_{c} n_{c} w_{c}\left(1-n_{r} w_{r}\right)} .
$$

With the parametrization in Equation 11:

$$
\frac{\partial \Omega}{\partial \lambda}=\frac{\left[k_{r}-\kappa k_{c}-(1-\kappa) k_{s}\right](N-1)}{(1-\lambda+\lambda N)\left[\kappa k_{c}+(1-\kappa) k_{s}\right]+(1-\lambda)(N-1) k_{r}+\kappa y z k_{c}}
$$

and

$$
\frac{\partial^{2} \Omega}{\partial \lambda \partial N}=\frac{\left[k_{r}-\kappa k_{c}-(1-\kappa) k_{s}\right]\left[\kappa k_{c}+(1-\kappa) k_{s}+\kappa y z k_{c}\right]}{\left\{(1-\lambda+\lambda N)\left[\kappa k_{c}+(1-\kappa) k_{s}\right]+(1-\lambda)(N-1) k_{r}+\kappa y z k_{c}\right\}^{2}} .
$$

\section{A.8. Proof of Corollary 2}

When $q_{r}=z=0$ and $k_{c}=k_{s}=\bar{k}_{m}$ Proposition 3 yields:

$$
\Omega=-\ln \left[1-(1-\lambda)\left(1-\frac{k_{r}}{\bar{k}_{m}}\right) n_{r} w_{r}\right] .
$$

The parametrization in Equation 11 yields the result in Corollary 2.

\section{A.9. Proof of Propositions 9 and 11}

The efficient level of investment is attained in equilibrium if and only if local financing is $\lambda^{*}$ such that

$$
\frac{\sum_{l} k_{l} q_{l} n_{l} w_{l}}{\sum_{l} q_{l} n_{l} w_{l}}=\frac{\left(1-\lambda^{*}\right) \sum_{l} k_{l} n_{l} w_{l}+\lambda^{*} \sum_{l \neq r} k_{l} n_{l} w_{l} /\left(1-n_{r} w_{r}\right)+y z k_{c} n_{c} w_{c}}{1+y z n_{c} w_{c}}
$$

or explicitly

$$
\lambda^{*}=\frac{1+y z n_{c} w_{c}}{\left(\bar{k}_{m}-k_{r}\right) n_{r} w_{r}}\left(\frac{\sum_{l} k_{l} q_{l} n_{l} w_{l}}{\sum_{l} q_{l} n_{l} w_{l}}-\frac{\sum_{l} k_{l} n_{l} w_{l}+y z k_{c} n_{c} w_{c}}{1+y z n_{c} w_{c}}\right),
$$

such that $\lambda^{*} \in[0,1]$ under the conditions given in Proposition 9. The comparative statics are given by

$$
\frac{1}{z} \frac{\partial \lambda^{*}}{\partial y}=\frac{1}{y} \frac{\partial \lambda^{*}}{\partial z}=\frac{n_{c} w_{c}}{\left(\bar{k}_{m}-k_{r}\right) n_{r} w_{r}}\left(\frac{\sum_{l} k_{l} q_{l} n_{l} w_{l}}{\sum_{l} q_{l} n_{l} w_{l}}-k_{c}\right)
$$

and

$$
\frac{\partial \lambda^{*}}{\partial k_{i}}=\frac{n_{i} w_{i}}{\left(\bar{k}_{m}-k_{r}\right) n_{r} w_{r}}\left[\frac{\left(1+y z n_{c} w_{c}\right) q_{i}}{\sum_{l} q_{l} n_{l} w_{l}}-1+\lambda^{*} \frac{\mathbf{1}_{i=r}-n_{r} w_{r}}{1-n_{r} w_{r}}-y z \mathbf{1}_{i=c}\right]
$$


such that solving out:

$$
\begin{aligned}
\frac{\partial \lambda^{*}}{\partial k_{c}} & =-\frac{\left(k_{s}-k_{r}\right)\left\{q_{s}-q_{c}+y z\left[q_{s}\left(1-n_{r} w_{r}\right)+q_{r} n_{r} w_{r}\right]\right\} \prod_{l} n_{l} w_{l}}{\left[\left(\bar{k}_{m}-k_{r}\right) n_{r} w_{r}\right]^{2}\left(1-n_{r} w_{r}\right) \sum_{l} q_{l} n_{l} w_{l}} \\
\frac{\partial \lambda^{*}}{\partial k_{s}} & =\frac{\left(k_{c}-k_{r}\right)\left\{q_{s}-q_{c}+y z\left[q_{s}\left(1-n_{r} w_{r}\right)+q_{r} n_{r} w_{r}\right]\right\} \prod_{l} n_{l} w_{l}}{\left[\left(\bar{k}_{m}-k_{r}\right) n_{r} w_{r}\right]^{2}\left(1-n_{r} w_{r}\right) \sum_{l} q_{l} n_{l} w_{l}}
\end{aligned}
$$

and

$$
\frac{\partial \lambda^{*}}{\partial k_{r}}=\frac{\left(k_{s}-k_{c}\right)\left\{q_{s}-q_{c}+y z\left[q_{s}\left(1-n_{r} w_{r}\right)+q_{r} n_{r} w_{r}\right]\right\} \prod_{l} n_{l} w_{l}}{\left[\left(\bar{k}_{m}-k_{r}\right) n_{r} w_{r}\right]^{2}\left(1-n_{r} w_{r}\right) \sum_{l} q_{l} n_{l} w_{l}} .
$$

Local decision-making coincides with the limit case $k_{r}=0$, which yields immediately Proposition 11.

\section{A.10. Proof of Proposition 12}

If $k_{c}>k_{s}>k_{r}$ then $\sum_{l}\left(k_{c}-k_{l}\right) q_{l} n_{l} w_{l}>0$. Hence, federal decision-making can attain the first best iff $\sum_{l} k_{l} q_{l} n_{l} w_{l} \geq \sum_{l} k_{l} n_{l} w_{l} \sum_{l} q_{l} n_{l} w_{l}$ and moreover

$$
\begin{aligned}
\underline{z} \equiv \max \left\{\frac{\sum_{l}\left(k_{l}-\bar{k}_{m}\right) q_{l} n_{l} w_{l}}{y n_{c} w_{c} \sum_{l}\left(k_{c}-k_{l}\right) q_{l} n_{l} w_{l}}, 0\right\} & \leq z \\
& \leq \bar{z} \equiv \frac{\sum_{l} k_{l} q_{l} n_{l} w_{l}-\sum_{l} k_{l} n_{l} w_{l} \sum_{l} q_{l} n_{l} w_{l}}{y n_{c} w_{c} \sum_{l}\left(k_{c}-k_{l}\right) q_{l} n_{l} w_{l}},
\end{aligned}
$$

such that

$$
\frac{\partial \bar{z}}{\partial k_{r}}=-\frac{\left(k_{c}-k_{s}\right)\left(q_{s}-q_{r}\right) \sum_{l} q_{l} n_{l} w_{l} \prod_{l} n_{l} w_{l}}{y\left[n_{c} w_{c} \sum_{l}\left(k_{c}-k_{l}\right) q_{l} n_{l} w_{l}\right]^{2}}<0 \text { for } q_{s}>q_{r}
$$

and if $\sum_{l}\left(k_{l}-\bar{k}_{m}\right) q_{l} n_{l} w_{l}>0$ then

$$
\frac{\partial \underline{z}}{\partial k_{r}}=\frac{\left(k_{c}-\bar{k}_{m}\right) q_{r} n_{r} w_{r} \sum_{l} q_{l} n_{l} w_{l}}{y n_{c} w_{c}\left[\sum_{l}\left(k_{c}-k_{l}\right) q_{l} n_{l} w_{l}\right]^{2}}>0
$$

so in general $\partial \underline{z} / \partial k_{r} \geq 0$.

If $k_{s} / k_{c}>1+q_{r} s_{r} /\left(q_{s} s_{s}\right)$ then $\sum_{l}\left(k_{c}-k_{l}\right) q_{l} n_{l} w_{l}<0$ for all $k_{r} \geq 0$. Then federal decision-making can attain the first best iff $\sum_{l}\left(\bar{k}_{m}-k_{l}\right) q_{l} n_{l} w_{l} \geq 0$ and moreover

$$
\begin{aligned}
\underline{z} \equiv \max \left\{\frac{\sum_{l} k_{l} n_{l} w_{l} \sum_{l} q_{l} n_{l} w_{l}-\sum_{l} k_{l} q_{l} n_{l} w_{l}}{y n_{c} w_{c} \sum_{l}\left(k_{l}-k_{c}\right) q_{l} n_{l} w_{l}}, 0\right\} & \leq z \\
& \leq \bar{z} \equiv \frac{\sum_{l}\left(\bar{k}_{m}-k_{l}\right) q_{l} n_{l} w_{l}}{y n_{c} w_{c} \sum_{l}\left(k_{l}-k_{c}\right) q_{l} n_{l} w_{l}},
\end{aligned}
$$

such that

$$
\frac{\partial \bar{z}}{\partial k_{r}}=-\frac{\left(\bar{k}_{m}-k_{c}\right) q_{r} s_{r} \sum_{l} q_{l} n_{l} w_{l}}{y n_{c} w_{c}\left[\sum_{l}\left(k_{l}-k_{c}\right) q_{l} n_{l} w_{l}\right]^{2}}<0
$$


and if $\sum_{l} k_{l} n_{l} w_{l} \sum_{l} q_{l} n_{l} w_{l}>\sum_{l} k_{l} q_{l} n_{l} w_{l}$ then

$$
\frac{\partial \underline{z}}{\partial k_{r}}=\frac{\left(k_{s}-k_{c}\right)\left(q_{s}-q_{r}\right) \sum_{l} q_{l} n_{l} w_{l} \prod_{l} n_{l} w_{l}}{y\left[n_{c} w_{c} \sum_{l}\left(k_{l}-k_{c}\right) q_{l} n_{l} w_{l}\right]^{2}}>0,
$$

so in general $\partial \underline{z} / \partial k_{r} \geq 0$.

A switch to local decision-making reduces $k_{r}$ to zero. In both cases, this widens the range $[\underline{z}, \bar{z}]$ and may even turn it from empty to non-empty given that $\sum_{l}\left(\bar{k}_{m}-k_{l}\right) q_{l} n_{l} w_{l} \geq 0$ is relaxed by lower $k_{r}$, and so is $\sum_{l} k_{l} q_{l} n_{l} w_{l} \geq \sum_{l} k_{l} n_{l} w_{l} \sum_{l} q_{l} n_{l} w_{l}$ for all $q_{r}<\sum_{l} q_{l} n_{l} w_{l}$.

\section{A.11. Proof of Propositions 14 and 15}

Proposition 14 follows immediately from Equation 21. Investment is decreasing in $\lambda$ if and only if $\bar{k}_{m}>k_{r}$. If $\sum_{l} k_{l} n_{l} q_{l} /\left(\sum_{l} n_{l} q_{l}\right)<k_{r}<\bar{k}_{m}$ then user fees increase investment for all $\lambda \in[0,1]$. This is helpful if $\lambda=v=0 \Rightarrow \Omega<0$, namely if

$$
\frac{\sum_{l} k_{l} q_{l} n_{l} w_{l}}{\sum_{l} q_{l} n_{l} w_{l}}<\frac{\sum_{l} k_{l} n_{l} w_{l}+y z k_{c} n_{c} w_{c}}{1+y z n_{c} w_{c}} .
$$

If $\sum_{l} k_{l} n_{l} q_{l} /\left(\sum_{l} n_{l} q_{l}\right)>\bar{k}_{m}>k_{r}$, then user fees reduce investment for all $\lambda \in[0,1]$. This is helpful if $\lambda=1>v=0 \Rightarrow \Omega>0$, namely if

$$
\frac{\sum_{l} k_{l} q_{l} n_{l} w_{l}}{\sum_{l} q_{l} n_{l} w_{l}}>\frac{\bar{k}_{m}+y z k_{c} n_{c} w_{c}}{1+y z n_{c} w_{c}} .
$$

\section{A.12. Proof of Proposition 16}

In a local political equilibrium with user fees, overinvestment equals:

$$
\begin{aligned}
\Omega=\ln & \frac{\sum_{l \neq r} k_{l} q_{l} n_{l} w_{l}}{\sum_{l} q_{l} n_{l} w_{l}} \\
& \quad-\ln \frac{v \sum_{l \neq r} k_{l} q_{l} n_{l} /\left(\sum_{l} q_{l} n_{l}\right)+(1-v)\left[1-(1-\lambda) n_{r} w_{r}\right] \bar{k}_{m}+y z k_{c} n_{c} w_{c}}{1+y z n_{c} w_{c}} .
\end{aligned}
$$

Thus, there is underinvestment for $\lambda_{L}=v=0$ if and only if

$$
\frac{\sum_{l \neq r} k_{l} q_{l} n_{l} w_{l}}{\sum_{l} q_{l} n_{l} w_{l}}<\frac{\bar{k}_{m}+y z k_{c} n_{c} w_{c}}{1+y z n_{c} w_{c}},
$$

and investment increases with user fees if and only if

$$
\frac{\sum_{l \neq r} k_{l} q_{l} n_{l}}{\sum_{l} q_{l} n_{l}}<\bar{k}_{m} .
$$

Both conditions are satisfied if and only if

$$
\begin{array}{r}
q_{r}>\bar{q}_{r} \equiv \max \left\{\frac{1}{n_{r} w_{r}}\left(\frac{1+y z n_{c} w_{c}}{\bar{k}_{m}+y z k_{c} n_{c} w_{c}} \sum_{l \neq r} k_{l} q_{l} n_{l} w_{l}-\sum_{l \neq r} q_{l} n_{l} w_{l}\right),\right. \\
\left.\frac{1}{n_{r}}\left(\frac{\sum_{l \neq r} k_{l} q_{l} n_{l}}{\bar{k}_{m}}-\sum_{l \neq r} q_{l} n_{l}\right)\right\},
\end{array}
$$


such that

$$
\frac{1}{y} \frac{\partial \bar{q}_{r}}{\partial z}=\frac{1}{z} \frac{\partial \bar{q}_{r}}{\partial y} \in\left\{\frac{\left(k_{s}-k_{c}\right) \sum_{l \neq r} k_{l} q_{l} n_{l} w_{l} \prod_{l \neq r} n_{l} w_{l}}{n_{r} w_{r}\left(1-n_{r} w_{r}\right)\left(\bar{k}_{m}+y z k_{c} n_{c} w_{c}\right)^{2}}, 0\right\}
$$

and

$$
\begin{aligned}
& \frac{1}{k_{s}} \frac{\partial \bar{q}_{r}}{\partial k_{c}}=-\frac{1}{k_{c}} \frac{\partial \bar{q}_{r}}{\partial k_{s}} \\
& \quad \in\left\{\frac{\left(1+y z n_{c} w_{c}\right) \prod_{l \neq r} n_{l} w_{l}}{n_{r} w_{r}\left(1-n_{r} w_{r}\right)} \frac{q_{c}-q_{s}\left[1+y z\left(1-n_{r} w_{r}\right)\right]}{\left(\bar{k}_{m}+y z k_{c} n_{c} w_{c}\right)^{2}}, \frac{n_{c} n_{s}}{n_{r} w_{r}\left(1-n_{r} w_{r}\right)} \frac{q_{c} w_{s}-q_{s} w_{c}}{\bar{k}_{m}^{2}}\right\} .
\end{aligned}
$$

\section{A.13. Proof of Proposition 17}

The only derivative that is not immediate is

$$
\frac{\partial z}{\partial k_{c}}=-\frac{\left[1+\lambda n_{r} w_{r} /\left(1-n_{r} w_{r}\right)\right] k_{s} n_{s} w_{s}+(1-\lambda) k_{r} n_{r} w_{r}}{\left[\lambda \bar{k}_{m}+(1-\lambda) \sum_{l} k_{l} n_{l} w_{l}\right]^{2}} \frac{i n_{c} w_{c} y}{C_{z z}(z, i)}<0 .
$$

Efficient nuisance mitigation is attained if

$$
\lambda=\lambda_{z}^{*} \equiv \frac{\left(k_{c}-k_{r}\right)\left(n_{s} w_{s}+n_{r} w_{r}\right)-\left(k_{s}-k_{r}\right) n_{s} w_{s}}{\left(k_{c}-k_{r}\right) n_{c} w_{c}+\left(k_{s}-k_{r}\right) n_{s} w_{s}} \frac{1-n_{r} w_{r}}{n_{r} w_{r}},
$$

such that

$$
\lambda_{z}^{*} \geq 0 \Leftrightarrow \frac{k_{c}-k_{r}}{k_{s}-k_{r}} \geq \frac{n_{s} w_{s}}{n_{s} w_{s}+n_{r} w_{r}}
$$

and

$$
\lambda_{z}^{*} \leq 1 \Leftrightarrow \frac{k_{c}-k_{r}}{k_{s}-k_{r}} \leq 1
$$

with derivatives

$$
\begin{aligned}
\frac{\partial \lambda_{z}^{*}}{\partial k_{c}} & =\frac{\left(k_{s}-k_{r}\right) n_{s} w_{s}}{\left[\left(k_{c}-k_{r}\right) n_{c} w_{c}+\left(k_{s}-k_{r}\right) n_{s} w_{s}\right]^{2}} \frac{1-n_{r} w_{r}}{n_{r} w_{r}}, \\
\frac{\partial \lambda_{z}^{*}}{\partial k_{s}} & =-\frac{\left(k_{c}-k_{r}\right) n_{s} w_{s}}{\left[\left(k_{c}-k_{r}\right) n_{c} w_{c}+\left(k_{s}-k_{r}\right) n_{s} w_{s}\right]^{2}} \frac{1-n_{r} w_{r}}{n_{r} w_{r}}
\end{aligned}
$$

and

$$
\frac{\partial \lambda_{z}^{*}}{\partial k_{r}}=\frac{\left(k_{c}-k_{s}\right) n_{s} w_{s}}{\left[\left(k_{c}-k_{r}\right) n_{c} w_{c}+\left(k_{s}-k_{r}\right) n_{s} w_{s}\right]^{2}} \frac{1-n_{r} w_{r}}{n_{r} w_{r}} .
$$

\section{A.14. Proof of Proposition 18}

For ease of notation, denote

$$
\bar{k}_{\tau} \equiv \lambda \bar{k}_{m}+(1-\lambda) \sum_{l} k_{l} n_{l} w_{l}
$$

such that

$$
\frac{\partial \bar{k}_{\tau}}{\partial \lambda}=\frac{n_{r} w_{r}}{1-n_{r} w_{r}} \sum_{l}\left(k_{l}-k_{r}\right) n_{l} w_{l} .
$$


When $C(z)$ is isoelastic, Equation 24 admits the explicit solution

$$
z=\zeta\left(\frac{\bar{k}_{\tau}}{k_{c}} \frac{\Phi}{n_{c} w_{c} y}\right)^{\frac{1}{1+\zeta}}
$$

such that

$$
\frac{\partial z}{\partial \lambda}=\frac{1}{1+\zeta} \frac{z}{\bar{k}_{\tau}} \frac{\partial \bar{k}_{\tau}}{\partial \lambda}
$$

and investment in mitigation is efficient if and only if $\bar{k}_{\tau}=k_{c}$

Then Equation 25 becomes

$$
\Gamma\left|T^{\prime}(i)\right| y \sum_{l} k_{l} q_{l} n_{l} w_{l}=\bar{k}_{\tau}+(1+\zeta)\left[\bar{k}_{\tau} \Phi\left(k_{c} n_{c} w_{c} y\right)^{\xi}\right]^{\frac{1}{1+\zeta}}
$$

such that

$$
\frac{\partial i}{\partial \lambda}=-\frac{1+\left[\Phi\left(k_{c} n_{c} w_{c} y / \bar{k}_{\tau}\right)^{\xi}\right]^{\frac{1}{1+\zeta}}}{\Gamma T^{\prime \prime}(i) y \sum_{l} k_{l} q_{l} n_{l} w_{l}} \frac{\partial \bar{k}_{\tau}}{\partial \lambda}
$$

and investment in construction is efficient if and only if

$$
\Omega=\ln \frac{\sum_{l} k_{l} q_{l} n_{l} w_{l}}{\sum_{l} q_{l} n_{l} w_{l}}-\ln \frac{\bar{k}_{\tau}+(1+\zeta)\left[\bar{k}_{\tau} \Phi\left(k_{c} n_{c} w_{c} y\right)^{\zeta}\right]^{\frac{1}{1+\zeta}}}{1+(1+\zeta)\left[\Phi\left(n_{c} w_{c} y\right)^{\zeta}\right]^{\frac{1}{1+\zeta}}}=0
$$

The optimum $\left(i^{*}, z^{*}\right)$ can be attained if and only if

$$
\frac{k_{c}-k_{r}}{k_{s}-k_{r}}=\frac{q_{s} n_{s} w_{s}}{q_{s} n_{s} w_{s}+q_{r} n_{r} w_{r}}
$$

which is certainly in $\left[n_{s} w_{s} /\left(n_{s} w_{s}+n_{r} w_{r}\right)\right.$, 1] if $0 \leq q_{r} \leq q_{s}$. If $\left(k_{c}-k_{r}\right) /\left(k_{s}-k_{r}\right)<$ $q_{s} n_{s} w_{s} /\left(q_{s} n_{s} w_{s}+q_{r} n_{r} w_{r}\right)$ then $z \geq z^{*} \Rightarrow i>i^{*}$. If $\left(k_{c}-k_{r}\right) /\left(k_{s}-k_{r}\right)>q_{s} n_{s} w_{s} /\left(q_{s} n_{s} w_{s}+\right.$ $\left.q_{r} n_{r} w_{r}\right)$ then $i \geq i^{*} \Rightarrow z>z^{*}$. 


\section{References}

[1] Altshuler, Alan, and David Luberoff. 2003. Mega-Projects: The Changing Politics of Urban Public Investment. Washington, DC: Brookings Institution Press.

[2] Baron, David P., and John A. Ferejohn. 1989. Bargaining in Legislatures. American Political Science Review 83(4): 1181-1206.

[3] Been, Vicki. 1994. Locally Undesirable Land Uses in Minority Neighborhoods: Disproportionate Siting or Market Dynamics? Yale Law Journal 103(6): 1383-1422.

[4] Besley, Timothy, and Stephen Coate. 2003. Centralized Versus Decentralized Provision of Local Public Goods: A Political Economy Approach. Journal of Public Economics 87(12): 2611-2637.

[5] Berry, Craig, Tom Hunt, and Laura White. 2015. Public Infrastructure Investment and Business Activity in the English Regions. SPERI British Political Economy Brief No. 15.

[6] Björkman, Martina, and Jakob Svensson. 2009. Power to the People: Evidence from a Randomized Field Experiment on Community-Based Monitoring in Uganda. Quarterly Journal of Economics 124(2): 735-769.

[7] Boehmer, Tegan K., Stephanie L. Foster, Jeffrey R. Henry, and Efomo L. WoghirenAkinnifesi. 2013. Residential Proximity to Major Highways: United States, 2010. Morbidity and Mortality Weekly Report Supplements 62(3): 46-50.

[8] Boffa, Federico, Amedeo Piolatto, and Giacomo A. M. Ponzetto. 2016. Political Centralization and Government Accountability. Quarterly Journal of Economics 131(1): $381-422$.

[9] Brinkman, Jeffrey C., and Jeffrey Lin. 2016. Freeway Revolts! Highways, Downtown Amenities, and Urban Growth. Working paper, Federal Reserve Bank of Philadelphia.

[10] Brueckner, Jan K. 2015. Decentralized Road Investment and Pricing in a Congested, Multi-Jurisdictional City: Efficiency with Spillovers. National Tax Journal 68(3S): 839854.

[11] Brueckner, Jan K., and Harris Selod. 2006. The Political Economy of Urban TransportSystem Choice. Journal of Public Economics 90(6): 983-1005.

[12] Caro, Robert. 1974. The Power Broker: Robert Moses and the Fall of New York. New York, NY: Knopf.

[13] Chang, Yun-chien. 2010. An Empirical Study of Compensation Paid in Eminent Domain Settlements: New York City, 1990-2002. Journal of Legal Studies 39(1): 201-244.

[14] Coate, Stephen, and Stephen Morris. 1995. On the Form of Transfers to Special Interests. Journal of Political Economy 103(6): 1210-1235. 
[15] Cox, Ed, and Bill Davies. 2013. Still on the Wrong Track: An Updated Analysis of Transport Infrastructure Spending. IPPR North Report.

[16] De Borger, Bruno, and Stef Proost. 2012. A Political Economy Model of Road Pricing. Journal of Urban Economics 71 (1): 79-92.

[17] De Borger, Bruno, and Stef Proost. 2016a. The Political Economy of Pricing and Capacity Decisions for Congestible Local Public Goods in a Federal State. International Tax and Public Finance 23 (5): 934-959.

[18] De Borger, Bruno, and Stef Proof. 2016b. Can We Leave Road Pricing to the Regions? The Role of Institutional Constraints. Regional Science and Urban Economics 60: 208222 .

[19] Duranton, Gilles and Matthew A. Turner. 2011. The Fundamental Law of Road Congestion: Evidence from US Cities. American Economic Review 101(6): 2616-2652.

[20] Ferraz, Claudio, and Frederico Finan. 2008. Exposing Corrupt Politicians: The Effects of Brazil's Publicly Released Audits on Electoral Outcomes. Quarterly Journal of Economics 123(2): 703-745.

[21] Galston, William A. 2001. Political Knowledge, Political Engagement, and Civic Education. Annual Review of Political Science 4(1): 217-234.

[22] Garin, Andrew. 2016. Putting America to Work, Where? The Limits of Infrastructure Construction as a Locally-Targeted Employment Policy. Taubman Center Working Paper No. 2016-01.

[23] Gavazza, Alessandro, and Alessandro Lizzeri. 2009. Transparency and Economic Policy. Review of Economic Studies 76(3): 1023-1048.

[24] Gentzkow, Matthew. 2006. Television and Voter Turnout. Quarterly Journal of Economics 121(3): 931-972.

[25] Gerber, Alan S., Dean Karlan, and Daniel Bergan. 2009. Does the Media Matter? A Field Experiment Measuring the Effect of Newspapers on Voting Behavior and Political Opinions. American Economic Journal: Applied Economics 1(2): 35-52.

[26] Glaeser, Edward L., and Giacomo A. M. Ponzetto. 2014. Shrouded Costs of Government: The Political Economy of State and Local Public Pensions. Journal of Public Economics 116: 89-105.

[27] Glaeser, Edward L., Giacomo A. M. Ponzetto, and Jesse M. Shapiro. 2005. Strategic Extremism: Why Republicans and Democrats Divide on Religious Values. Quarterly Journal of Economics 120(4): 1283-330.

[28] Glaeser, Edward L., and Bryce A. Ward. 2009. The Causes and Consequences of Land Use Regulation: Evidence from Greater Boston. Journal of Urban Economics 65(3): 265-278. 
[29] Gyourko, Joseph, Albert Saiz, and Anita A. Summers. 2008. A New Measure of the Local Regulatory Environment for Housing Markets: The Wharton Residential Land Use Regulatory Index. Urban Studies 45: 693-729.

[30] Hamilton, James T. 1995. Testing for Environmental Racism: Prejudice, Profits, Political Power? Journal of Policy Analysis and Management 14(1): 107-132.

[31] Hartgen, David T., and M. Gregory Fields. 2016. 22nd Annual Highway Report: The Performance of State Highway Systems. Reason Foundation Policy Study No. 448.

[32] Lindbeck, Assar, and Jörgen W. Weibull. 1987. Balanced Budget Redistribution and the Outcome of Political Competition. Public Choice 52(3): 273-297.

[33] Knight, Brian. 2005. Estimating the Value of Proposal Power. American Economic Review 95(5): 1639-1652.

[34] Knight, Brian. 2006. Common Tax Pool Problems in Federal Systems. In Democratic Constitutional Design and Public Policy: Analysis and Evidence, edited by Roger D. Congleton and Birgitta Swedenborg. Cambridge, MA: MIT Press.

[35] Milligan, Kevin, Enrico Moretti, and Philip Oreopoulos. Does Education Improve Citizenship? Evidence from the United States and the United Kingdom. Journal of Public Economics 88(9): 1667-1695.

[36] Munch, Patricia. 1976. An Economic Analysis of Eminent Domain. Journal of Political Economy 84(3): 473-498.

[37] Parker, Jennifer D., Nataliya Kravets, Keeve Nachman, and Amir Sapkota. Linkage of the 1999-2008 National Health and Nutrition Examination Surveys to Traffic Indicators from the National Highway Planning Network. National Health Statistics Report No. 45.

[38] Ponzetto, Giacomo A. M. 2011. Heterogeneous Information and Trade Policy. CEPR Discussion Paper No. 8726.

[39] Strömberg, David. 2004. Radio's Impact on Public Spending. Quarterly Journal of Economics 119(1): 189-221.

[40] Van Geelen, Hinko. 2012. Abating Annoyance Caused by Infrastructure Works. Procedia - Social and Behavioral Sciences 48 (Transport Research Arena 2012): 580-588.

[41] Weingast, Barry R. 1979. A Rational Choice Perspective on Congressional Norms. American Journal of Political Science 23: 245-263.

[42] Weingast, Barry R., Kenneth A. Shepsle and Christopher Johnsen. 1981. The Political Economy of Benefits and Costs: A Neoclassical Approach to Distributive Politics. Journal of Political Economy 89(4): 642-664. 